\title{
Innate promiscuity of the CYP706 family of P450 enzymes provides a suitable context for the evolution of dinitroaniline resistance in weed
}

Fatemeh Abdollahi $^{\mathrm{a}, \mathrm{b}, \mathrm{c}}$, Mohammad Taghi Alebrahim ${ }^{\mathrm{b} *}$, Chheng Ngov $^{\mathrm{c}}$, Etienne Lallemand ${ }^{\mathrm{d}}$, Younxiang Zheng ${ }^{\mathrm{c}}$, Claire Villette ${ }^{\mathrm{a}}$, Julie Zumsteg ${ }^{\mathrm{a}}$, François Andréd ${ }^{\mathrm{d}}$, Nicolas Navrot ${ }^{\mathrm{a}}$, Danièle Werck-Reichhart ${ }^{\mathrm{a} *}$, Laurence Miesch ${ }^{\mathrm{c} *}$

${ }^{a}$ Institut de Biologie Moléculaire des Plantes du Centre National de la Recherche Scientifique (CNRS), Unité Propre de Recherche 2357, Université de Strasbourg, France.

${ }^{\mathrm{b}}$ Department of Agronomy and Plant Breeding, Faculty of Agricultural Sciences \& Natural Resources, University of Mohaghegh Ardabili, Ardabil, Iran.

${ }^{c}$ Equipe de Synthèse Organique et Phytochimie, Institut de Chimie, Unité Mixte de Recherche 7177, CNRS, Université de Strasbourg, France.

${ }^{\mathrm{d}}$ Institute for Integrative Biology of the Cell (I2BC), Commissariat à l'Energie Atomique (CEA), CNRS, Université Paris-Saclay, 91198 Gif-sur-Yvette, France.

*Authors for correspondence:

Danièle Werck

Tel: $+33(0) 613549086$

Email: werck@unistra.fr

Laurence Miesch

Email:lmiesch@unistra.fr

Mohammad Taghi Alebrahim

Email:m.t.alebrahim@gmail.com

Keywords: cytochrome P450 oxygenases, dinitroanilines, enzyme promiscuity, evolution of weed herbicide resistance, herbicide metabolism, terpenoid metabolism 


\section{Summary}

- Increased metabolism is one of the main causes for evolution of herbicide resistance in weeds, a major challenge for sustainable food production. The molecular drivers of this evolution are poorly understood. We tested here the hypothesis that a suitable context for the emergence of herbicide resistance could be provided by plant enzymes with high innate promiscuity with regard to their natural substrates.

- A selection of yeast-expressed plant cytochrome P450 enzymes with well documented narrow to broad promiscuity when metabolizing natural substrates was tested for herbicide metabolism competence. The positive candidate was assayed for capacity to confer herbicide tolerance in Arabidopsis thaliana.

- Our data demonstrate that A. thaliana CYP706A3, with the most promiscuous activity on monoand sesquiterpenes for flower defense, can also oxidize plant microtubule assembly inhibitors, dinitroanilines. Ectopic overexpression of CYP706A3 confers dinitroaniline resistance. We show, in addition, that the capacity to metabolize dinitroanilines is shared by other members of the CYP706 family from plants as diverse as eucalyptus and cedar.

- Supported by 3D modelling of CYP706A3, the properties of enzyme active site and substrate access channel are discussed together with the shared physicochemical properties of the natural and exogenous substrates to explain herbicide metabolism. 


\section{Introduction}

Emergence of herbicide resistance in weeds provides a good example of ongoing, humandriven evolution. Although weeds are the primary cause of crop yield loss worldwide, in the context of growing demand for food and pesticide use reduction, it is essential to understand how herbicide resistance occurs. Herbicide resistance has been spreading around the world, since the introduction of 2,4-dichlorophenoxyacetic acid (2,4-D) as a first selective herbicide in 1947 (Switzer, 1957; Whitehead and Switzer, 1963). Several mechanisms of resistance have been reported (Powles and Yu, 2010; Délye et al., 2013; Cummins et al., 2014), but enhanced metabolism is the most complex and challenging. It often results in herbicide treatment-selected accumulation of multiple dominant or semi-dominant alleles conferring mild herbicide tolerance, which is particularly favored in outcrossing species. Enhanced metabolism is supported by large families of enzymes with often redundant and/or promiscuous activities, and potentially leads to cross-resistance to herbicides with different modes of action, including not yet marketed compounds (Délye et al., 2013; Yu and Powles, 2014). Cytochrome P450 monooxygenases feature among the main contributors to metabolism-mediated resistance (Yu and Powles, 2014; Pan et al., 2019; Gaines et al., 2020).

Complementary strategies can be employed to discover the metabolic determinants of herbicide resistance. One is a genetic, biochemical, and transcriptomic approach of resistant weed populations to identify the enzymes responsible for the herbicide metabolism (Yu and Powles, 2014; Gaines et al., 2014; Pan et al., 2019). The discovery of the enzymes responsible for herbicide resistance can also be guided by the prior identification of enzymes conferring increased herbicide tolerance to crop plants (Pan et al., 2006; Iwakami et. al., 2014). This approach recently led to the characterization of a subfamily of grass-specific P450 enzymes with a puzzling promiscuity, with the capacity to metabolize a broad range of active compounds with different mode of actions and contrasting physicochemical properties (Iwakami et al., 2014; Iwakami et al., 2019; Guo et al., 201; Han et al., 2020). A third strategy is to screen for herbicide metabolism a range of representative and functionally characterized enzymes. This strategy holds the potential to link the metabolism of specific classes of herbicides with the catalytic properties, physiological and ecological functions of individual or clades of enzymes. It is expected to reveal the genetic backgrounds allowing evolution of herbicide metabolism, and to offer a support to appraise the ecological side-effects of herbicide treatments on weeds and crops. 
The best documented example of this approach is provided by the CYP76 family of cytochromes P450 involved in the metabolism of monoterpenols in many plant species. When CYP76B1 was first shown to metabolize phenylurea herbicides, no physiological function was associated with this enzyme from Helianthus tuberosus. CYP76B1-mediated herbicide metabolism resulted in nonphytotoxic di- $N$-dealkylated metabolites and in significant tolerance to phenylurea herbicides in transgenic tobacco (Nicotiana tabacum) and Arabidopsis thaliana (Robineau et al., 1998; Didierjean et al., 2002). It was then reported that several members of the CYP76 family in Catharanthus roseus, A. thaliana, or grapevine catalyzed different oxidation reactions on monoterpenols, including sequential reactions and conversion of different related compounds (Collu et al., 2001; Hoefer et al., 2013; Ginglinger et al., 2013; Miettinen et al., 2014; Ilc et al., 2017). Most notably, CYP76C1 from A. thaliana was associated with the conversion of volatile linalool into more soluble carboxylinalool and lilac oxides in the opening flower for protection against florivorous insects (Boachon et al., 2015). Meanwhile, the work of Höfer et al. (2014) bridged Arabidopsis CYP76C activities on monoterpenols and phenylurea herbicides, demonstrating that the enzymes of the CYP76C subfamily supported both the hydroxylation of monoterpenols and the dealkylation or hydroxylation of phenylurea, and conferred phenylurea tolerance to ectopically overexpressing A. thaliana lines. CYP76s form a fast-blooming family of genes (Nelson and Werck-Reichhart, 2011) encoding moderately promiscuous enzymes. This led us to postulate that P450s in highly diversified families or encoded by recent gene duplicates under relaxed selective pressure, which show more promiscuous catalytic properties, might be more prone to metabolize exogenous compounds, and thus to contribute to the evolution of herbicide resistance.

The aim of this study was therefore to investigate if P450-mediated herbicide metabolism could be related to innate catalytic promiscuity. To this end, we assessed the metabolism of a set of active compounds representative of the most commonly used classes of herbicides by six plant cytochrome P450 enzymes with documented biochemical activities and, for most of them, known physiological functions in plant (Table 1). These candidates were selected to be representative of P450s with very low to high promiscuity with regard to natural substrates. This investigation reveals a novel activity of the promiscuous terpenoid-oxidizing P450 enzyme CYP706A3 of $A$. thaliana on dinitroanilines, and demonstrates that CYP706A3 holds the innate capacity to enhance the plant tolerance to most of the members of this class of herbicides. We show that the capacity 
to metabolize dinitroanilines extends to other CYP706 enzymes from Alaska cedar and eucalyptus. Results are discussed in light of enzyme and substrate structural/biophysical properties and adaptive evolution.

\section{Materials and Methods}

\section{Herbicides assayed for plant $\mathbf{P 4 5 0}$ metabolism}

All the herbicides were purchased from Sigma-Aldrich (Saint Louis, USA). The full list of herbicides used in this experiment is provided in Supporting Information Table S1. Two mM stock solutions were prepared in methanol $96 \%(\mathrm{v} / \mathrm{v})$ and stored in the dark at $4^{\circ} \mathrm{C}$.

\section{Transgenic plant lines}

The source and validation of Arabidopsis thaliana CYP706A3 T-DNA insertion and 35S:CY706A3 overexpressing lines are described in Boachon et al. (2019).

\section{Enzyme expression in yeast and isolation of recombinant enzyme-containing microsomal fractions}

Production of recombinant enzymes in Saccharomyces cerevisiae was carried according to (Pompon et al., 1996). Construction of the expression vectors of CYP71D51, CYP76B1, CYP72A224, CYP73A92, CYP98A23/A27 and CYP706A3 were previously described in Gavira et al., 2013, Robineau et al., 1998, Miettinen et al., 2014, Renault et al., 2017, Alber et al., 2019, and Boachon et al., 2019, respectively. Construction of the plasmids for the expression of CYP706C55 and CYP706M1 have been described in (Hansen et al., 2018) and (Cankar et al., 2014), respectively. Yeast transformation and preparation of yeast microsomes were previously described (Ginglinger et al., 2013; Liu et al., 2016). P450 concentration was evaluated according to were according to Omura and Sato (1964).

\section{Assays of herbicide conversion with yeast microsomes}

The screening for herbicide conversion was carried out in a final volume of $100 \mu \mathrm{l}$ containing

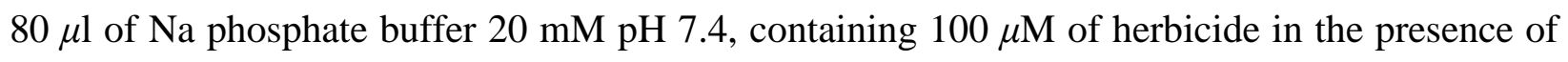
$300 \mu \mathrm{M}$ of NADPH and $10 \mu \mathrm{l}$ of yeast microsomal membranes. The incubation was carried out at 
$25^{\circ} \mathrm{C}$ for $20 \mathrm{~min}$ and stopped with $200 \mu \mathrm{l}$ of acetonitrile/ $\mathrm{HCl}(99: 1$, v/v). The mixture was centrifuged at 15,000 $\mathrm{g}$ for $5 \mathrm{~min}$ and supernatant analyzed on an Alliance 2695 Waters high performance liquid chromatography (HPLC) apparatus set with a C18 column $(5 \mu \mathrm{m}, 100 \AA$, 150 $\mathrm{mm}, 4.6 \mathrm{~mm}$, Kinetex) using a binary gradient system of solvents A (water containing 0.1\% (v/v) formic acid) and B (100\% HPLC-grade acetonitrile containing 0.1\% (v/v) formic acid) as follows: 0 to $5 \mathrm{~min} 10 \%$ to $50 \% \mathrm{~B}$, then, 5 to $15 \mathrm{~min} 50 \%$ to $95 \% \mathrm{~B}$, hold for $2 \mathrm{~min}$, followed by $95 \%$ to $10 \%$ for $1 \mathrm{~min}$, hold for $1 \mathrm{~min}$. Flow rate was $1 \mathrm{ml} \cdot \mathrm{min}^{-1}$ and column temperature $35^{\circ} \mathrm{C}$. The formation of products was monitored with a diode array absorbance detector from 220 to $400 \mathrm{~nm}$. Assays were conducted in triplicate.

\section{Herbicide conversion in whole yeast}

Yeast colonies were inoculated into $30 \mathrm{ml} \mathrm{SGI} \mathrm{medium}(0.7 \%(\mathrm{w} / \mathrm{v})$ yeast extract, $0.1 \%(\mathrm{w} / \mathrm{v})$ bacto casamino acids, $0.002 \%(\mathrm{v} / \mathrm{v})$ tryptophan, $2 \%(\mathrm{w} / \mathrm{v})$ glucose) and grown at $28^{\circ} \mathrm{C}$ for $24 \mathrm{~h}$ with shaking $(180 \mathrm{rpm})$. The overnight culture was diluted into $200 \mathrm{ml}$ of YPGE (1\% (w/v) yeast extract, $1 \%(\mathrm{w} / \mathrm{v})$ peptone, $3 \%(\mathrm{v} / \mathrm{v})$ ethanol, $0.5 \%(\mathrm{w} / \mathrm{v})$ glucose $)$. Cells were grown at $28^{\circ} \mathrm{C}$ with shaking at $180 \mathrm{rpm}$ until cell density reached an $\mathrm{OD}_{600}$ of 0.7 to 0.9 . $\mathrm{P} 450$ expression was induced adding $10 \mathrm{ml}$ of $200 \mathrm{~g} .1^{-1}$ galactose at room temperature for 24 hours. To test herbicide conversion, $5 \mathrm{ml}$ of $200 \mu \mathrm{M}$ herbicide were added to the culture medium, further incubated overnight at room temperature with shaking. The yeast cells were then harvested by centrifugation (15 min at 2,800 $\mathrm{g}$ and $4^{\circ} \mathrm{C}$ ), and the supernatant was collected. The pelleted yeast cells were resuspended in $500 \mu \mathrm{l}$ of methanol $(99: 1, \mathrm{v} / \mathrm{v})$, vortexed and left 30 for minutes at room temperature. After $10 \mathrm{~min}$ centrifugation at $15,000 \mathrm{~g}$, the supernatant was recovered and analyzed by HPLC. Fifty $\mathrm{ml}$ of culture medium were extracted and concentrated using solid-phase extraction (SPE) on SPE cartridges (Oasis HLB $3 \mathrm{cc}, 60 \mathrm{mg}$; Waters) preconditioned with $5 \mathrm{ml}$ of methanol, then $5 \mathrm{ml}$ of water. Flow-rate of the samples on the cartridges was $7 \mathrm{ml} . \mathrm{min}^{-1}$. Compounds retained on the column were eluted with $2 \mathrm{ml}$ of methanol. Eluates were analyzed on an Alliance 2695 Waters HPLC apparatus, as described in the herbicide in vitro conversion section. In some cases, when handling of a large number of samples was required, the culture medium was directly analyzed by HPLC without prior concentration.

\section{Tests of herbicide tolerance}


Seeds of $A$. thaliana Col-0 ecotype and of the CYP706A3 T-DNA insertion and overexpression lines were sterilized in ethanol 70\% (v/v), SDS 0.05\% (w/v) for $20 \mathrm{~min}$. Sterilized seeds were sown on solid medium containing 8 g.l $\mathrm{l}^{-1}$ agar and $2.45 \mathrm{~g} . \mathrm{l}^{-1}$ Murashige and Skoog including vitamins (Duchefa-Biochemie), adjusted to $\mathrm{pH}$ 5.8. Plants were grown in growth chambers with a light intensity of 70 to $90 \mathrm{mmol} \cdot \mathrm{m}^{-2} \cdot \mathrm{s}^{-1}$ at $22^{\circ} \mathrm{C}$ during the $16 \mathrm{~h}$ day period and at $20^{\circ} \mathrm{C}$ during the $8 \mathrm{~h}$ night period. After germination, plantlets were transferred to a new plate of the same medium with herbicides and further grown for 15 days. Data were analyzed with a nonlinear regression by fitting to the four-parameter log-logistic dose-response model (Streibig et al. 1993):

$$
y=d+\frac{c-d}{1+\left(\frac{x}{e}\right)^{b}}
$$

where $\mathrm{y}$ is the weed fresh weight expressed as a percentage of the control, $\mathrm{c}$ is the lower limit,d is the upper limit, $\mathrm{b}$ is the slope of the curve, $\mathrm{x}$ is the herbicide dose or concentration, and e (IC50) is the herbicide dose or concentration required to inhibit weed growth by $50 \%$ of the control. The tolerance factor was calculated by dividing the $\mathrm{IC}_{50}$ value of $C Y P 706 A$ to $\mathrm{IC}_{50}$ of the wild-type. All statistical analyses were performed using $\mathrm{R}$ version 4.0.2.

\section{Leaf disc assay}

Transient expression of the genes of interest in Nicotiana benthamiana leaves was performed as described in (Boachon et al., 2019). Leaf discs (20 per sample) were placed in $10 \mathrm{ml}$ of $20 \mathrm{mM}$ pH 7.4 Na phosphate citrate buffer containing $200 \mu \mathrm{M}$ of herbicides in a Petri dish, exposed to vacuum twice, and placed in a growth chamber at $20^{\circ} \mathrm{C}$ with a photoperiod of $16 / 8 \mathrm{~h}$ light/dark for $24 \mathrm{~h}$. Leaf discs were directly ground in $4 \mathrm{ml}$ methanol with a mortar and pestle. The extracts were centrifuged $5 \mathrm{~min}$ at 15,000 g, and supernatants analyzed on an Alliance 2695 Waters HPLC system as above. Incubation media of the leaf discs were separately analyzed by HPLC after centrifugation for $1 \mathrm{~min}$ at $500 \mathrm{~g}$. Assays were conducted in triplicate.

\section{Thin-layer and silica column chromatography}

Thin-layer chromatography (TLC) was performed using Merck-TLC Silica gel $60 \mathrm{~F}_{254}$ aluminum plates. The plates were developed in a mobile phase containing petroleum ether and ethyl acetate in ratio of 70:30. After drying, plates were revealed either with sulfuric vanillin, with 
a $\mathrm{KMnO}_{4}$ solution, or with a mixture of phosphomolybdic acid-cerium sulfate followed by heating using a heat gun, and read under UV light. Preparative thin-layer chromatography was performed using 20 X $20 \mathrm{~cm}$ silica gel 60 F254 Merck-glass plates, $0.5 \mathrm{~mm}$ thick. Merck Geduran® 40-63 $\mu \mathrm{m}$ silica gel was used for column chromatography. The crude material was purified by column chromatography using a step gradient of ethyl acetate in petroleum ether ( 0 to $10 \%, \mathrm{v} / \mathrm{v}$ ) to afford hydroxylated pendimethalin compounds.

\section{Liquid chromatography (LC) acquisition for mass spectrometry (MS)}

Extracts were analyzed using LC coupled to high resolution mass spectrometry (HRMS) on a DioneX Utlimate 3000 (Thermo) coupled to a Q-TOF Impact II (Bruker). Chromatographic separation was achieved using an Acquity UPLC BEH C18 column (100 x 2.1 mm, $1.7 \mu \mathrm{m}$; Waters) and pre-column. The mobile phase consisted of (A) water and (B) methanol, both containing $0.1 \%$ formic acid. The run started by 2 min of $95 \%$ A, then a linear gradient was applied to reach $100 \%$ $\mathrm{B}$ at $10 \mathrm{~min}$, followed by isocratic run using B during $3 \mathrm{~min}$. Return to initial conditions was achieved in $1 \mathrm{~min}$, with a total runtime of $15 \mathrm{~min}$. The column was operated at $35^{\circ} \mathrm{C}$ with a flowrate of $0.30 \mathrm{ml} \cdot \mathrm{min}^{-1}$.

The spectrometer was used in positive ion mode, with a spectra rate of $2 \mathrm{~Hz}$ on a mass range from 20 to $1000 \mathrm{Da}$. The capillary voltage was set at $2500 \mathrm{~V}$, the nebulizer at 2 Bars and the dry gas at $81 . \mathrm{min}^{-1}$, with a dry temperature of $200{ }^{\circ} \mathrm{C}$. Fragments were obtained via auto-MS/MS with a MS/MS collision energy ramping from 18 to $45 \mathrm{eV}$ depending on the mass of the parent ion. Data processing is described in Supporting information Method S1.

\section{Nuclear magnetic resonance (NMR)}

NMR spectra were recorded using a Bruker AV-300, AV-400, or AV-500 spectrometer with the solvent residual peak as internal standard. Splitting patterns were reported as s, singlet; $d$, doublet; t, triplet; q, quartet; m, multiplet and br, broad singlet.

\section{Homology modeling of CYP706A3}

Homology modeling and preparation of CYP706A3 structure for docking studies were performed according to the protocol described in Boachon et al. (2019), modified with the following adjustments. The multiple sequence alignment of the three templates CYP2R1 (pdb 
3czh), CYP17A1 (pdb 5irq), and CYP1A2 (pdb 2hi4) used for Modeller 9v18 was that calculated solely by Promals3D (Pei et al., 2008), to which was added a new template corresponding to a single heme compound with the geometry and charges calculated by DFT by Shahrokh et al. (2012). The resulting alignment with the heme parametrized was then submitted to Modeller, and a python script was subsequently applied to the best model for assigning to the heme the electrostatic charges of Shahrokh et al. (2012), in the Fe(III) ground or compound I states. The model selected was the best compromise between the Dope score of Modeller and the QMEANDisco score (0.68) calculated by Swissmodel (Studer et al., 2020).

\section{Docking of herbicides}

Molecular docking experiments with herbicide molecules into the CYP706A3 active site were performed using Smina (Koes et al., 2013) a fork of the open source docking program AutoDock Vina (Trott et al., 2010, release 1.1.2) in the semi-flexible mode (rigid receptor), and prepared with AutoDock Tools (Morris et al., 2009). Ligand molecules were built using ChemDraw, and optimized and parameterized under the UCSF Chimera molecular modeling suite using AM1-BCC charges model, and the structure files saved under MOL2 format as input files for AutoDock Vina. For the receptor, the MOL2 format files were created by Chimera (charges generated with AMBER ff14), and converted into the PDBQT format file by AutoDockTools (ADT), without using the charge calculation provided by ADT. For ligand structures, partial charges were finally assigned using MMF94 force field under Avogadro software after different tests based on the pendimethalin know metabolism. In all docking runs, the receptor was kept rigid, and the ligand fully flexible. The docking box included the active site with the iron-protoporphyrin group on one edge, and the whole distal moiety of the enzyme, including access channels and protein surface, to allow a large sampling of potential poses. The grid built by AutoGrid included 60, 60 and 60 points in x, y and

$\mathrm{z}$ directions, with a grid spacing of $0.37 \AA$. The procedure is further detailed in Supporting Information Methods S2. 


\section{Results}

\section{Screening for herbicide P450-dependent herbicide metabolism}

The investigated P450s were selected on the basis of their catalytic activities, so as to be representative of enzymes with different substrate permissiveness, ranging from 1) highly specific for a single natural substrate (represented by CYP73A92, a cinnamic acid hydroxylase in the phenylpropanoid pathway (Renault et al., 2017)), to 2) enzymes reported to show a very high promiscuity with regard to physiological substrates (exemplified by CYP706A3, previously reported to oxidize more than 20 sesqui- and mono-terpenes in vivo (Boachon et al., 2019)). In the case of CYP98s, two paralogs were included in the screening, one of them with low permissiveness and under positive selection, the second corresponding to a recent duplication of the latter, for which selection pressure was relaxed and showing, accordingly, increased promiscuity (Alber et al. 2019). Both of them, however, were reported to metabolize large hydrophilic substrates (Alber et al. 2019). We first tested herbicide metabolism using microsomal membranes purified from yeasts transformed with the genes encoding the different candidates, to be able to check for successful enzyme expression. The expression of the respective P450 enzymes was checked by differential spectrophotometry (Omura and Sato, 1964). All the investigated enzymes were successfully detected and quantified in yeast membranes (Fig. 1a-e; Supporting Information Table S2).

To determine the capacity of the candidates to catalyze herbicide oxidation, microsomal membranes were then incubated with NADPH and herbicides representative of the major classes of active compounds (Supporting Information Table S1). Membranes from yeast transformed with an empty vector were used as a control. Samples were analyzed by high performance liquid chromatography with diode-array detection (HPLC-DAD). This initial screening (Supporting Information Table S3) confirmed the already reported activity of the Helianthus tuberosus CYP76B1 (used as a positive control) with regard to phenylurea herbicides (Robineau et al., 1998; Didierjean et al., 2002), and revealed a novel oxidative activity of Arabidopsis thaliana CYP706A3 on pendimethalin (Fig. 2). However, the amounts of herbicide conversion products obtained under these conditions were not sufficient for the full characterization of the products.

\section{Pendimethalin is converted by CYP706A3 in whole yeast and Nicotiana benthamiana}


For confirmation the activity of CYP706A3 and generation of oxidation products in amounts sufficient for structural characterization, pendimethalin conversion was further assayed using whole transgenic yeast cultures and transient CYP706A3 expression in N. benthamiana.

For the whole yeast conversion assays, after induction of the protein expression with galactose, herbicide was added to the culture medium. Pendimethalin and conversion products were extracted after 24 hours, separately from the yeast cells or the culture medium. From the yeast cell extract, pendimethalin conversion products were recovered, but in small amounts (Fig. 3a). Conversely, in the extract of the culture medium, no residual pendimethalin was detected, but large amounts of two conversion products showing absorption and retention times identical to those previously obtained with the yeast membranes were observed (Fig. 3a; Supporting Information Fig. S1).

CYP706A3 was also transiently expressed by infiltration of transformed Agrobacterium in the leaves of $N$. benthamiana. Leaf discs were excised 5 days post-agroinfiltration, vacuum-infiltrated with pendimethalin, and further incubated for 24 hours. Products were separately extracted from the leaf discs and incubation medium for analysis by HPLC-DAD. Only low amounts of herbicide conversion products were detected in the leaf disc extracts (Fig. 3b). Still, analysis of the extracts from the incubation medium confirmed the CYP706A3-dependent conversion of pendimethalin (Fig. 3b), with the detection of the same two products as in yeast assays, but in lower amounts.

Therefore, whole yeast conversion was upscaled to generate metabolites in sufficient amounts for structural identification.

\section{Products of CYP706A3-mediated pendimethalin conversion are two diastereoisomers}

In a first step to product characterization, liquid chromatography coupled to mass spectrometry (LC-MS) analysis was carried out. It suggested that the two peaks resulting from the CYP706A3-mediated pendimethalin conversion were oxygenated products with the same mass and fragmentation patterns (Fig. 3c; Supporting Information Fig. S2), hydroxylated on the side chain in the terminal or subtermminal position.

Unambiguous product identification required nuclear magnetic resonance (NMR) characterization, and thus larger amounts of pure compounds. Pooled methanol extracts of whole yeast conversion were analyzed by thin-layer chromatography (TLC). Two major and two minor products more hydrophilic than pendimethalin were detected (Supporting Information Fig. S3a). 
The two major products, with close $\mathrm{R}_{\mathrm{f}}$ values, were then separated by preparative TLC, eluted, and submitted to NMR analysis. Both ${ }^{1} \mathrm{H}-\mathrm{NMR}$ and ${ }^{13} \mathrm{C}-\mathrm{NMR}$ spectra of the purified compounds were consistent with the prior LC-MS results, indicating that pendimethalin was hydroxylated by CYP706A3 on the subterminal carbon of the side-chain (Supporting Information Fig. S3b and c; Supporting Information Note S1). Hydroxylation resulted in the formation of two stereocenters. The two products are thus most likely diastereoisomers .

For a final check if the two TLC-purified products were those identified as products via LC, they were injected separately and simultaneously on LC-DAD and compared to the elution profile of a whole yeast assay (Supporting Information Fig. S4). This experiment confirmed that the major TLC-purified products corresponded to the peaks $\mathbf{1}$ and $\mathbf{2}$ detected in LC. This allowed us to determine the catalytic parameters of the CYP706A3-mediated pendimethalin 4-hydroxylation using the yeast microsome assay. The reaction proceeded with a $K_{m}$ of $436( \pm 140) \mu \mathrm{M}$ and a $k_{c a t}$ of $2.34( \pm 0.44) \mathrm{min}^{-1}$ (Supporting Information Fig. S5).

\section{CYP706A3 oxidizes most herbicides belonging to the class of dinitroanilines}

CYP706A3 was previously shown to oxidize a broad spectrum of more than twenty terpenoids, including both sesqui- and mono-terpenes (Boachon et al, 2019) in Arabidopsis flowers. We thus set out to determine whether CYP706A3 was also able to convert a range of dinitroanilines. To this end, we tested the metabolism of ethalfluralin, fluchloralin, trifluralin, benefin and oryzalin using a whole yeast conversion experiment. HPLC-DAD profiles of the yeast incubation media extracts obtained from CYP706A3- and empty vector-transformed yeasts were compared. Expression of $C Y P 706 A 3$ resulted in a decrease in the active compound and the concomitant formation of more polar products for ethalfluralin, fluchloralin, trifluralin and benefin, but not for oryzalin (Fig. 4). For several dinitroanilines (e.g. fluchloralin, benefin and ethalfluralin), the formation of more than one potential polar product was detected (Fig. 4; Supporting Information Fig. S6). LC-MS/MS search for potential conversion products indicated that those were essentially mono- and di-oxygenated products (Supporting Information Fig. S6).

The whole yeast assays were clearly more effective to detect CYP706A3-mediated herbicide conversion than tests using purified microsomal membranes. A screening to detect the metabolism 
of compounds in Supporting Information Table S1 was thus performed a second time using the whole yeast assay. It did not detect conversion of any further active compound.

\section{CYP706A3 ectopic expression increases dinitroaniline tolerance in A. thaliana}

The CYP706A3 expression in the wild-type Arabidopsis plants has been previously investigated (Boachon et al., 2019) and shown to be restricted to developing and mature inflorescences, low in flower buds with a sharp increase at anthesis. Ectopic overexpression of phenylurea-oxidizing P450 enzymes has been previously reported to increase herbicide tolerance in tobacco and Arabidopsis (Didierjean et al., 2002; Höfer et al., 2014). This led us to postulate that a change in CYP706A3 expression might lead to an increase in dinitroaniline resistance. To test this hypothesis and determine whether CYP706A3-dependent metabolism of dinitroanilines incurs herbicide detoxification in the plant, a genetically engineered Arabidopsis line overexpressing CYP706A3 (Boachon et al., 2019) was tested for herbicide tolerance. As shown in Fig. 5, a concentration of $0.1 \mu \mathrm{M}$ of pendimethalin, ethalfluralin, fluchloralin, trifluralin or benefin, which resulted in almost total inhibition of the growth of wild-type Arabidopsis, did not affect 355S:CYP706A3 transformed plants. Conversely, no significant difference between wild-type and 35S:CYP706A3 plants was observed with oryzalin. Transformation with a vector expressing the bar gene (conferring resistance to phosphinothricin) and a P450 that does not metabolize dinitroanilines (CYP73A94; Renault et al., 2017) does not alter herbicide tolerance (Supporting Information Fig. S7).

To determine the gain in herbicide tolerance conferred by CYP703A6 ectopic expression, we compared the effect of a stepwise increase herbicide concentration on wild-type and transformed plant growth (Fig. 6a-f). Tolerance factors calculated from this experiment indicated an increase in tolerance of about 52-fold to pendimethalin, 12-fold to fluchloralin, 10-fold to trifluralin and 7fold to ethalfluralin and benefin for 35S:CYP706A3 seedlings compared to wild-type (Supporting

Information Table S4). Conversely, no increase in herbicide tolerance was confirmed for oryzalin.

To confirm herbicide conversion, methanol extracts of pendimethalin-treated Arabidopsis seedling were analyzed by HPLC-DAD. No residual herbicide was detected in the plants, nor primary metabolites previously identified after yeast and conversion, indicating further herbicide metabolism in the transformed plants. 


\section{Structural basis for herbicide metabolism by CYP706A3}

The results of Autodock 4 docking experiments of six dinitroanilines into the active site cavity of the rebuilt 3D of CYP706A3 are displayed Fig. 7 and Supporting Information Fig. S8. Altogether, they indicate a good affinity of the active site for all the compounds investigated. The empirical affinity score given by Autodock, normalized on well-characterized protein complexes, can be considered as an estimated free energy of ligand binding, and the energy values in a homogeneous family of molecules can be compared. The docking of all compounds resulted in similar overall binding affinity for lowest energy and most populated clusters of poses, and for clusters involving hydroxylation of hydrocarbons. Pendimethalin and oryzalin exhibited the best

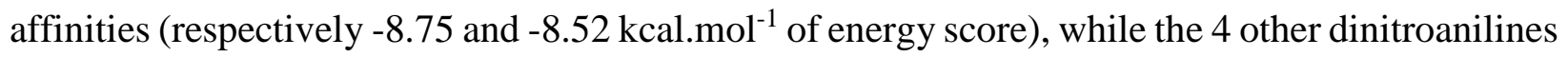
displayed homogeneous affinities ranging from -7.3 to $-7.9 \mathrm{kcal}^{\mathrm{mol}}{ }^{-1}$. For productive poses, i.e. yielding to a metabolism on a $\mathrm{CH}$ site, the most predominant poses for all molecules oriented the alkyl chains towards the heme iron in the active site. In some cases (pendimethalin, oryzalin), the lowest energy and most populated clusters corresponded to poses where the subterminal $\mathrm{CH}_{2}$ and terminal $\mathrm{CH}_{3}$ groups were distant from the heme iron at about $3 \AA$, highly favorable for oxidative attack. The equidistance indicates that the metabolism can occur either on the two carbon sites with the same probability, and when the subterminal group $\mathrm{CH}_{2}$ is closer, the hydroxylation introduces a chirality on the oxidized carbon and can lead to two diastereoisomers. For other molecules, the same positions of metabolism were found in lowest energy clusters involving $\mathrm{CH}$ proximity, with an additional possible metabolism on the subterminal position in benefin molecule $\left(\mathrm{CH}_{2}\right.$ group, third pose, Supporting Information Fig. S8).

It must be mentioned that the preparation of all ligands (conformational and partial charges optimization) involved the neutral form (no global charge) of the molecules. The docking process could have considered the positive isomer for oryzalin, of which the sulfonamide group is likely to be ionized at physiological $\mathrm{pH}$. This docking has not been considered due to the high hydrophobicity of access channels characterized in the model protein (Boachon et al., 2019). In its neutral form, oryzalin exhibited a good binding affinity, with prevalent oxidation on the two terminal carbons of the alkyl chain. Compared to other molecules, oryzalin was the only one to be bound through an ionic and electrostatic interaction of the opposite moiety (which bears the sulfonamide group) with hydrophilic Asn 122 and Asp128 residues located at the top of the active 
site cavity (Supporting Information Fig. S9). This can explain its improved affinity compared to the majority of other dinitroanilines.

Based on docking experiments we would thus expect an efficient metabolism of oryzalin by CYP706A3. In an attempt to understand the absence of oryzalin conversion observed experimentally, we compared the relative water solubilities, LogPs, and dissociation constants $(p K a)$ of the set of dinitroanilines investigated and main reported natural CYP706A3 substrates. As shown in Table 2, the water solubility of oryzalin is significantly higher than those of the other dinitroanilines investigated, and those of the reported terpenoid substrates. Its $p K a$ is 9.8 instead

of the negative range for the metabolized compounds. Its topological polar surface area is $163 \AA^{2}$ versus $104 \AA^{2}$ for pendimethalin. Interestingly, a comparison of the properties of the natural and herbicide substrates of CYP706A3 and CYP76 enzymes (Table 2) shows that they form very distinct classes of compounds.

Physicochemical properties of natural and exogenous compounds thus appear as decisive factors of their P450-mediated metabolism, most likely since they determine their access to the active site.

\section{Dinitroaniline conversion capacity is present in other sesquiterpene metabolizing $\mathbf{P 4 5 0}$ enzymes}

Structural data suggest that dinitroaniline oxidation by CYP706A3 might be associated with the size and hydrophobicity of its active site, and possibly also with the size and hydrophobicity of its access channels (Boachon et al., 2019). Such properties are expected to be shared with other members of the CYP706 family and/or other sesquiterpenoid metabolizing P450 enzymes. To test this hypothesis, we assayed the capacity of other P450 enzymes, belonging to the CYP706 and CYP71 families, isolated from different plant species and previously reported to oxidize sesquiterpenoids (CYP706M1 from Alaska cedar (Callitropsis nootkanensis), Cankar et al., 2014 ; CYP71D51 from A. thaliana, Gavira et al., 2013) or other small volatile compounds (CYP706C55 catalyzing phenylacetaldoxime dehydration in Eucalyptus cladocalyx, Hansen et al., 2018) to convert dinitroanilines. They were expressed in yeast, and dinitroaniline conversion was evaluated in the incubation medium using the whole yeast assay, primarily based on the decrease in active compound. As show in Fig. 8, all the tested enzymes, but more notably the two members of the CYP706 family from Alaska cedar and eucalyptus, were able to metabolize dinitroanilines, 
although with higher selectivity with regard to the different active compounds than CYP706A3. The reaction was then upscaled to compare the reaction products via HPLC-DAD and LC-MS (Supporting Information Figs. S6 and S10-11). This experiment confirmed divergent substrateand regio-specificities of the four enzymes, revealing that they formed different oxidation products. CYP706M1 from Alaska cedar was the most active for trifluralin conversion, while CYP706AC55 from eucalyptus was the only one showing a trace of activity on oryzalin. 


\section{Discussion}

Evolution of P450-mediated herbicide resistance in weeds is still poorly understood. It is well established that resistance most often results from the selection pressure exerted by repeated herbicide treatments, but the molecular mechanisms leading to this resistance are not fully revealed. The mechanisms proposed include nucleotide mutation/polymorphism within P450 genes, gene duplication or changes in gene regulation (resulting from increased expression or modification of expression pattern). It is still unclear if herbicide metabolism is principally associated with specific families/classes of P450 enzymes showing unusual promiscuity, with P450 gene families present in high copy in the plant genomes, or with accumulation of weak resistance alleles in the same plant. Another pending question is whether the metabolism of specific herbicide chemistries can be related to the metabolism of particular endogenous compounds because of structural similarities.

In this study, our aim was to test the hypothesis that the propensity of P450 enzymes to convert herbicides might be related to their intrinsic promiscuity with regard to natural compounds. Our data reveal the capacity of a subset of P450 enzymes sharing a common preference for small hydrophobic substrates to convert and detoxify the active compounds belonging to the class of dinitroanilines.

Dinitroanilines are pre-emergence, soil-incorporated microtubule inhibitors used to control annual grass and certain dicot weeds in several major crops, especially wheat, soybean and cotton. Dinitroaniline-resistant populations have been reported in weeds as diverse as Alopecurus myosuroides (James et al., 1995), Lolium rigidum (McAlister et al., 1995; Broster et al., 2013; Owens et al., 2014; Chen et al., 2018a,b, 2019, 2020), Eleusine indica (Mudge et al., 1994), Setaria viridis (Morrison et al., 1994), Amaranthus palmeri (Gossett et al., 1992), Poa annua (Lowe et al., 2001) and Alopecurus aequalis (Hashim et al., 2012). In many cases, this resistance was shown to result from mutations in one of the target genes, $\alpha$-tubulin (Anthony et al., 1998; Yamamoto et al., 1998; Délye et al., 2004; Hashim et al., 2012; Chen et al., 2018a, 2020; Chu et al., 2018; Chen et al., 2020). Still, more recent investigations on Australian trifluralin resistant populations of $L$. rigidum point to metabolism as the most frequent cause of the resistance in this weed (Chen et al., 2018b), and the synergy between trifluralin and the insecticide phorate suggests P450-mediated metabolism in several multi-resistant populations (Busi et al., 2017). Still, no specific P450 enzyme/gene was so far associated with dinitroaniline metabolism. 
The prototype P450 shown in this study to metabolize dinitroanilines is CYP706A3, an enzyme specifically expressed in the flowers of A. thaliana (mainly at anthesis) to decrease the emission of small volatile terpenes and to convert them into terpene oxides for flower defense against florivores. As previously shown by Boachon et al. (2019), this enzyme oxidizes more than 20 natural compounds, both mono- and sesquiterpenes with quite diverse structures, but all sharing a small size and high hydrophobicity (Fig. 9). The structure of the main natural CYP706A3 primary products have been characterized as (+)-1-oxo-thujopsene and diastereoisomers of (+)-6oxo- $\alpha$-barbatene and (+)-6-OH- $\alpha$-barbatene. It was also show that the latter were further oxidized by CYP706A3 (Boachon et al., 2019). This enzyme thus displays an exceptional permissiveness with regard to small volatile compounds, which most likely also explains its capacity to process dinitroanilines. Alike C10 and C15 terpene olefins, the latter are small and very hydrophobic (Fig. 9). Trifluralin was reported to be volatile (Chen et al., 2018a). When oxidizing pendimethalin, CYP706A3 forms two diastereoisomers, hydroxylated on the subterminal position of the sidechain. It also oxidizes most of the other dinitroanilines, including ethalfluralin, benefin, fluchloralin, trifluralin, in most cases generating several products. An exception is oryzalin that is not converted by CYP706A3.

Most of these experimental data are well supported by the structure of the active site of CYP706A3, as previously modelled by Boachon et al. (2019), which is essentially lined by hydrophobic residues (implying low selectivity). This active site offers low energy docking poses at distances allowing oxidative attack to many terpene olefins and oxides, with positions fitting experimental data (Boachon et al., 2019). In the same way, docking experiments in the 3D model of the CYP706A3 predict a most favorable pose of pendimethalin leading to attack of the subterminal carbons of both branches of the symmetrical side chain, as experimentally determined. Also several favorable poses are obtained for the other dinitroanilines with asymmetrical sidechains, in agreement with our experimental herbicide conversion results. Unexpected, though, was the effective docking of oryzalin for which we obtained low energy docking poses in the active site of CYP706A3, but which is not converted by the enzyme. An explanation for this apparent conflict seems to be provided by the physical properties of oryzalin and of the substrate access channels of CYP706A3. Modelling of the CYP706A3 3D structure has previously identified two access channels to the active site. Both were narrow and essentially lined with hydrophobic residues, hence adapted for specific access of small and hydrophobic compounds. They were, in 
addition, oriented to the membrane or the membrane surface (Boachon et al., 2019). Contrary to other dinitroanilines, hydrophobic, with low water solubilities and unlikely to dissociate, oryzalin is water soluble due to its sulfonamide substituent and expected to be protonated at physiological $\mathrm{pH}$ (Table 2). It can thus be hypothesized that the hydrophilicity and charge of oryzalin prevents its access to the active site and effective processing by CYP706A3. This statement has two important consequences: the first is that oryzalin might be effective on weeds resistant to other dinitroanilines; the second is that this knowledge might help to design new active compounds less prone to evolve a resistance.

More importantly for the evolution of weed resistance, we also demonstrate that the CYP706A3-dependent metabolism of dinitroanilines results in herbicide detoxification. This is evidenced by the increase in herbicide tolerance observed in Arabidopsis seedlings when CYP706A3 is expressed under the control of a CaMV35S promoter that shifts protein expression to the vegetative organs of the plant (Fig. 5). The gain in herbicide resistance well correlates with CYP706A3-dependent herbicide metabolism detected in transformed yeast. It ranges from 7-fold for benefin and ethalfluralin to 52-fold in the case of pendimethalin, comparable to resistances reported in weeds as a result of target-site mutation (Chen et al., 2018a, 2020). This is achieved despite a rather modest catalytic efficiency for the hydroxylation of pendimethalin. Our data thus provide a direct evidence that the modification and increase in native gene expression that extends the enzyme production from the flower tissues (as naturally occurs in the wild-type) to the vegetative parts of the plant is sufficient to confer herbicide tolerance. Such a change in enzyme expression might be a common source of emergence of herbicide resistance in weeds, especially when submitted to repeated selection.

The capacity to metabolize dinitroanilines is not restricted to CYP706A3. The structural properties of the active site and access channels of CYP706A3, including size, hydrophobicity, and their associated enzyme promiscuity, can be assumed to be shared by other P450 enzymes metabolizing terpenes olefins or other small hydrophobic compounds. We thus postulated that other terpene-metabolizing P450s might be able to convert dinitroanilines. This assumption seems to be correct. CYP706M1 and CYP71D51 are sesquiterpene-metabolizing enzymes previously isolated from Alaska cedar (Cankar et al, 2014) and Arabidopsis (Gavira et al., 2013), respectively, and CYP706C55 from eucalyptus is reported to dehydrate phenylacetaldoxime (Hansen et al., 2018). We show that all of them metabolize dinitroanilines (Fig. 8). This suggests that a large 
number of P450s from very diverse plant species, especially when belonging to the CYP706 family (including subfamilies from distant taxa such Rosidae and Gymnospems), can potentially contribute to the evolution of dinitroaniline resistance. It is interesting to note that the P450 enzymes investigated, with distinct substrate preferences for terpene olefins, also show contrasting preferences for dinitroaniline herbicides and generate different conversion products (Supporting Information Figs. 6 and 9).

We previously showed that several members of the CYP76 family from different plant sources, having as natural function the oxidation of monoterpenols, were metabolizing the herbicides belonging to the chemical group of phenylurea (Robineau et al., 1998; Didierjean et al., 2002; Höfer et al., 2014). In this study, we demonstrate that P450 enzymes oxidizing mono-and sesquiterpenes as natural substrates and belonging to the CYP706 and CYP71 families hold the potential to metabolize and detoxify dinitroanilines. In both cases, P450 families showing high taxa-specific gene duplications in plant genomes (so-called blooms) and clear promiscuity with regard to their natural substrates are involved. In both cases also, the currently emerging picture is that a compatibility between the properties of the active sites/substrate access channels and the respective chemistries of natural and herbicide substrates is required for effective metabolism. This suggests that common size and physicochemical properties shared by natural and xenobiotic substrates might prevail over structural analogies to favor metabolism.

Altogether, our data start to reveal the correlations existing between herbicide metabolism and P450 ecological functions, such as plant defense against insects and control of microbial communities (Höfer et al., 2014; Boachon et al., 2015; Boachon et al., 2019). These studies should help to anticipate negative side-effects of herbicide treatments on natural plant defense and associated fitness costs. Beyond providing a description of enzymes potentially responsible for metabolic resistance, structural models for the educated design of synergists, and a phylogenetic/genomic background, this work, bridging herbicide metabolism with innate ecological functions, will thus help understand resistance mechanisms and evolution in weeds, building-up the theoretical basis for extending herbicide longevity and developing better weed management strategies. 
Acknowledgments: We are grateful to Drs J Beekwilder and EHJ Neilson, respectively, for kindly providing the CYP706M1 and CYP706C55 yeast expression vectors. FaA thanks University of Mohaghegh Ardabili for $\mathrm{PhD}$ funding and University of Strasbourg for support to international mobility. We are grateful to BASF SE-Ludwigshafen for generous gifts of pendimethalin.

Author contribution: DW-R, NN, LM, FrA, MTA designed and supervised the research; FaA, CN, EL, CV, FrA performed experiments; FaA, CV, LM analyzed the data; MTA, provided financial support; FaA, FrA, DW-R wrote the paper.

\section{References}

Alber AV, Renault H, Basilio-Lopes A, Bassard J, Liu Z, Ullmann P, Lesot A, Bihel F, Schmitt M, Werck-Reichhart D, Ehlting J. 2019. Evolution of coumaroyl conjugate 3hydroxylases in land plants: lignin biosynthesis and defense. The Plant Journal 99: 924-936.

Anthony RG, Waldin TR, Ray JA, Bright SW and Hussey PJ. 1998. Herbicide resistance caused by spontaneous mutation of the cytoskeletal protein tubulin. Nature 393: 260-263.

Batard Y, LeRet M, Schalk M, Zimmerlin A, Durst F, Werck-Reichhart D. 1998. Molecular cloning and functional expression in yeast of CYP76B1, a xenobiotic-inducible 7ethoxycoumarin $O$-deethylase from Helianthus tuberosus. The Plant Journal 14:111-120.

Boachon B, Junker RR, Miesch L, Bassard JE, Höfer R, Caillieaudeaux R, Seidel DE, Lesot A, Heinrich C, Ginglinger JF, Allouche L, Vincent B, Wahyuni DS, Paetz C, Beran F, Miesch M, Schneider B, Leiss K, Werck-Reichhart D. 2015. CYP76C1 (cytochrome P450)-mediated linalool metabolism and the formation of volatile and soluble linalool oxides in Arabidopsis flowers: a strategy for defense against floral antagonists. Plant Cell 27: 29722990.

Boachon B, Burdloff Y, Ruan J, Rojo R, Junker R, Vincent B, Nicolè F, Bringel F, Lesot A, Henry L, Bassard JE, Mathieu S, Allouche F, Kaplan I, Dudareva N, Vuilleumier S, Miesch L, André F, Navrot N, Chen XY, Werck-Reichhart D. 2019. A promiscuous 
CYP706A3 reduces terpene volatile emission from Arabidopsis flowers, affecting florivores and the floral microbiome. Plant Cell 12: 2947-2972.

Broster JC, Koetz EA, Wu H. 2013. Herbicide resistance levels in annual ryegrass (Lolium rigidum Gaud.) and wild oat (Avena spp.) in southwestern New South Wales. Plant Protection Science 28: 126-142.

Busi R, Gaines TA, Powles S. 2017. Phorate can reverse P450 metabolism-based herbicide resistance in Lolium rigidum. Pest Management Science 73: 410-417.

Cankar K, van Houwelingen A, Goedbloed M, Renirie R, de Jong R M, Bouwmeester H, Bosch B, Sonke T, Beekwilder J. 2014. Valencene oxidase CYP706M1 from Alaska cedar (Callitropsis nootkatensis). FEBS Letters 588: 1001-1007.

Chen Ja , Goggin D, Han H, Busi R, Yu Q, Powles S. 2018. Enhanced trifluralin metabolism can confer resistance in Lolium rigidum. Journal of Agricultural and Food Chemistry 66: 75897596.

Chen $\mathbf{J}^{\mathrm{b}}$, Yu Q, Owen M, Han H, Powles SB. 2018. Dinitroaniline herbicide resistance in a multiple-resistant Lolium rigidum population. Pest Management Science 74: 925-932.

Chen J, Lu H, Han H, Yu Q, Sayer C, Powles S. 2019. Genetic inheritance of dinitroaniline resistance in an annual ryegrass population. Plant Science 283:189-194.

Chen J, Chu Z, Han H, Goggin DE, Yu Q, Sayer C, Powles SB. 2020. A Val-202-Phe $\alpha$-tubulin mutation and enhanced metabolism confer dinitroaniline resistance in a single Lolium rigidum population. Pest Management Science 76: 645-652.

Chu Z, Chen J, Nyporko A, Han H, Yu Q, Powles S. 2018. Novel $\alpha$-tubulin mutations conferring resistance to dinitroaniline herbicides in Lolium rigidum. Frontiers in Plant Science 9: 97.

Collu G, Unver N, Peltenburg-Looman AMG, van der Heijden R, Verpoorte R, Memelink J. 2001. Geraniol 10-hydroxylase, a cytochrome $\mathrm{P} 450$ enzyme involved in terpenoid indole alkaloid biosynthesis. FEBS Lett. 508: 215-220. 
Cummins I, Wortley DJ, Sabbadin F, He Z, Coxon CR, Straker HE, Sellars JD, Knight K, Edwards L, Hughes D, Kaundun SS, Hutchings SJ, Steel PG, Edwards R. 2013. Key role for a glutathione transferase in multiple-herbicide resistance in grass weeds. Proceedings of the National Academy of Sciences USA 110: 5812-5817.

Délye C, Menchari Y, Michel S, Darmency H. 2004. Molecular bases for sensitivity to tubulin-binding herbicides in green foxtail. Plant Physiology 136: 3920-3932.

Délye C, Jasieniuk M, Le Corre V. 2013. Deciphering the evolution of herbicide resistance in weeds. Trends in Genetics 29: 649-658.

Didierjean L, Gondet L, Perkins R, Lau SC, Schaller H, O'Keefe DP, Werck-Reichhart D. 2002. Engineering herbicide metabolism in tobacco and Arabidopsis with CYP76B1, a cytochrome P450 enzyme from Jerusalem artichoke. Plant Physiology 130:179-189.

Dimaano NG, Yamaguchi T, Fukunishi K, Tominaga T, Iwakami S. 2020. Functional characterization of cytochrome P450 CYP81A subfamily to disclose the pattern of crossresistance in Echinochloa phyllopogon. Plant Molecular Biology 102: 403-416.

Gaines TA, Lorentz L, Figge A, Herrmann J, Maiwald F, Ott MC, Han H, Busi R, Yu Q, Powles SB, Beffa R. 2014. RNA-Seq transcriptome analysis to identify genes involved in metabolism-based diclofop resistance in Lolium rigidum. The Plant Journal 78: 865-876.

Gaines TA, Duke SO, Morran S, Rigon CAG, Tranel PJ, Küpper A, Dayan FE. 2020. Mechanisms of evolved herbicide resistance. Journal of Biological Chemistry 295:1030710330.

Gavira C, Höfer R, Lesot A, Lambert F, Zucca J, Werck-Reichhart D. 2013. Challenges and pitfalls of P450-dependent (+)-valencene bioconversion by Saccharomyces cerevisiae. Metabolic Enineering 18: 25-35.

Ginglinger JF, Boachon B, Höfer R, Paetz C, Köllner TG, Miesch L, Lugan R, Baltenweck R, Mutterer J, Ullmann P, Beran F, Claudel P, Verstappen F, Fischer MJ, Karst F, Bouwmeester H, Miesch M, Schneider B, Gershenzon J, Ehlting J, Werck-Reichhart 
D. 2013. Gene coexpression analysis reveals complex metabolism of the monoterpene alcohol linalool in Arabidopsis flowers. Plant Cell 25: 4640-4657.

Gossett BJ, Murdock EC, Toler JE. 1992. Resistance of Palmer amaranth (Amaranthus palmeri) to the dinitroaniline herbicides. Weed Technology 6: 587-591.

Guo F, Iwakami S, Yamaguchi T, Uchino A, Sunohara Y, Matsumoto H. 2019. Role of CYP81A cytochrome P450s in clomazone metabolism in Echinochloa phyllopogon. Plant Science 283: 321-328.

Han H, Yu Q, Beffa R, González S, Maiwald F, Wang J, Powles SB. 2020. Cytochrome P450 CYP81A10v7 in Lolium rigidum confers metabolic resistance to herbicides across at least five modes of action. The Plant Journal. doi: 10.1111/tpj.15040.

Hansen C, Sørensen M, Veiga T, Zibrandtsen J, Heskes A, Olsen C, Boughton B, Møller B, Neilson E. 2018. Reconfigured cyanogenic glucoside biosynthesis in Eucalyptus cladocalyx involves a cytochrome P450 CYP706C55. Plant Physiology 178: 1081-1095.

Hashim S, Jan A, Sunohara Y, Hachinohe M, Ohdan H, Matsumoto H. 2012. Mutation of alpha-tubulin genes in trifluralin-resistant water foxtail (Alopecurus aequalis). Pest Management Science 68: 422-429.

Höfer R, Boachon B, Renault H, Gavira C, Miesch L, Iglesias, J, Ginglinger JF, Allouche L, Miesch M, Grec S, Larbat R, Werck-Reichhart D. 2014. Dual function of the cytochrome P450 CYP76 family from Arabidopsis thaliana in the metabolism of monoterpenols and phenylurea herbicides. Plant Physiology 166: 1149-1161.

Iwakami S, Endo M, Saika H, Okuno J, Nakamura N, Yokoyama M, Watanabe H, Toki Akira Uchino S, Inamura T. 2014. Cytochrome P450 CYP81A12 and CYP81A21 are associated with resistance to two acetolactate synthase inhibitors in Echinochloa phyllopogon. Plant Physiology 165: 618-629.

Iwakami S, Kamidate Y, Yamaguchi T, Ishizaka M, Endo M, Suda H, Nagai K, Sunohara Y, Toki S, Uchino A, Tominaga T, Matsumoto H. 2019. CYP81A P450s are involved in 
concomitant cross-resistance to acetolactate synthase and acetyl-CoA carboxylase herbicides in Echinochloa phyllopogon. New Phytologist 221: 2112-2122.

James EH, Kemp MS, Moss SR. 1995. Phytotoxicity of trifluoromethy- and methyl- substituted dinitroaniline herbicides on resistant and susceptible populations of black-grass (Alopecurus myosuroides). Pest Management Science 43: 273-277.

Lowe DB, Swire-Clark, McCarty LB, Whitwell T, Baird WV. 2001. Biology and molecular analysis of dinitroaniline-resistant Poa аппиа L. International Turfgrass Society Research Journal 9: 1019-1025.

Ilc T, Halter D, Miesch L, Lauvoisard F, Kriegshauser L, Ilg A, Baltenweck R, Hugueney P, Werck-Reichhart D, Duchêne E, Navrot N. 2017. A grapevine cytochrome P450 generates the precursor of wine lactone, a key odorant in wine. New Phytologist 213: 264-274.

McAlister FM, Holtum JA, Powles SB. 1995. Dinitroaniline herbicide resistance in rigid ryegrass (Lolium rigidum). Weed Science 43 :55-62.

Miettinen K, Dong L, Navrot N, Schneider T, Burlat V, Pollier J, Woittiez L, van der Krol S, Lugan R, Ilc T, Verpoorte R, Oksman-Caldentey KM, Martinoia E, Bouwmeester H, Goossens A, Memelink J, Werck-Reichhart D. 2014. The seco-iridoid pathway from Catharanthus roseus. Nature Communications 5: 3606- 3618.

Morris GM, Huey R, Lindstrom W, Sanner MF, Belew RK, Goodsell DS, Olson AJ. 2009. AutoDock4 and AutoDockTools4: Automated docking with selective receptor flexibility. Computers \& Chemistry 30: 2785-2791.

Morrison IN, Todd BG, Nawolsky KM. 1994. Confirmation of trifluralin resistant green foxtail (Setaria viridis) in Manitoba. Weed Technology 3:544-551.

Mudge LC, Gossett BJ, Murphy TR. 1994. Resistance of goosegrass (Eleusine indica) to dinitroaniline herbicides. Weed Science 32:591-594.

Nelson D, Werck-Reichhart D. 2011. A P450-centric view of plant evolution. Plant Journal 66: 194-211. 
Omura T, Sato R. 1964. The carbon monoxide-binding pigment of liver microsomes. Journal Biological Chemistry 239: 2370-2378.

Owen MJ, Martinez NJ, Powles SB. 2014. Multiple herbicide-resistant Lolium rigidum (annual ryegrass) now dominates across the Western Australian grain belt. Weed Research 54: 314-324.

Pan G, Zhang X, Liu K, Zhang J, Wu X, Zhu J, Tu J. 2006. Map-based cloning of a novel rice cytochrome $\mathrm{P} 450$ gene $C Y P 81 A 6$ that confers resistance to two different classes of herbicides. Plant Molecular Biology 61:933-943.

Pan L, Yu Q, Han H, Mao L, Nyporko A, Fan L, Bai L, Powles S. 2019. Aldo-keto reductase metabolizes glyphosate and confers glyphosate resistance in Echinochloa colona. Plant Physiology 181: 1519-1534.

Pei J, Kim B-H, Nick V. Grishin NV. 2008. PROMALS3D: a tool for multiple sequence and structure alignment. Nucleic Acids Res. 36: 2295-2300

Pompon D, Louerat B, Bronine A, Urban P. 1996. Yeast expression of animal and plant P450s in optimized redox environments. Method in Enzymology 272: 51-64.

Powles SB, Yu Q. 2010. Evolution in action: plants resistant to herbicides. Annual Reviews in Plant Biology 61: 317-347.

Renault H, De Marothy M, Jonasson G, Lara P, Nelson DR, Nilsson I, André F, von Heijne G, Werck-Reichhart D. 2017. Gene duplication leads to altered membrane topology of a cytochrome P450 enzyme in seed plants. Molecular Biology and Evolution 34: 2041-2056.

Robineau T, Batard Y, Nedelkina S, Cabello-Hurtado F, LeRet M, Sorokine O, Didierjean L, Werck-Reichhart D. 1998. The chemically inducible plant cytochrome P450 CYP76B1 actively metabolizes phenylureas and other xenobiotics. Plant Physiology 118:1049-56.

Shahrokh K, Orendt A, Yost GS, Cheatham TE. 2012. Quantum mechanically derived AMBER-compatible heme parameters for various states of the cytochrome P450 catalytic cycle. Computers \& Chemistry 33: 119-133. 
Streibig J.C, Rudemo M, Jensen E.J. 1993. Dose-response curves and statistical models. In: Herbicide Bioassay (ed. By streibig J. C. and P. Kudsk). CRC Press, Boca Raton, FL, 29-55.

Studer G, Rempfer C, Waterhouse A., Gumienny G, Haas J, Schwede T. 2020. QMEANDisCo - distance constraints applied on model quality estimation. Bioinformatics 36: 1765-1771.

Switzer CM. 1957. The existence of 2.4-D resistant strains of wild carrot. 11t. Northeastern Weed Control Conference 11: 315-318.

Whitehead CW, Switzer CM. 1963. The differential response of strains of wild carrot to 2,4-D and related herbicides. Plant Science 43: 255-262.

Yamamoto E, Zeng L, Baird WV. 1998. $\alpha$-Tubulin missense mutations correlate with antimicrotubule drug resistance in Eleusine indica. Plant Cell 10: 297-308.

Yu Q, Powles S. 2014. Metabolism-based herbicide resistance and cross-resistance in crop weeds: a threat to herbicide sustainability and global crop production. Plant Physiology 166:11061118. 
Table 1. Cytochrome P450 enzymes tested for herbicide conversion.

\begin{tabular}{lllll}
\hline CYP & Plant & $\begin{array}{l}\text { Reported } \\
\text { substrates }\end{array}$ & Promiscuity & References \\
\hline CYP73A92 & $\begin{array}{l}\text { Brachypodium } \\
\text { distachyon }\end{array}$ & Phenolics & - & (Renault et al., 2017) \\
CYP98A23 & Populus trichocarpa & Phenolics & - & (Alber et al., 2019) \\
CYP72A224 & Catharanthus roseus & Iridoids & - & (Miettinen et al., 2014) \\
CYP98A27 & Populus trichocarpa & Phenolics & + - & (Alber et al., 2019) \\
& & Monoterpenols & & (Batard et al., 1998; \\
CYP76B1 & Helianthus tuberosus & Alkoxycoumarin & + & Robineau et al., 1998; \\
& & Alkoxyresorufin & & Hoefer et al., 2014) \\
CYP706A3 & Arabidopsis thaliana & Terpenoids & +++ & (Boachon et al., 2019) \\
\hline
\end{tabular}


Table 2. Physical properties of dinitroaniline herbicides and natural substrates of CYP706A3 and CYP76 enzymes. In gray oryzalin is not a substrate for CYP706A3.

\begin{tabular}{|c|c|c|c|c|}
\hline Herbicide & $\begin{array}{c}\begin{array}{c}\text { Water solubility } \\
(\mathrm{mg} / \mathrm{L})\end{array} \\
\end{array}$ & $\log P$ & $p K a$ & References \\
\hline \multicolumn{5}{|c|}{ Natural substrates of CYP706A3 } \\
\hline Thujopsene & Insoluble & 4.56 & N/A & Chemeo \\
\hline Barbatene & Insoluble & 4.56 & N/A & Chemeo \\
\hline Thujene & Insoluble & 3 & N/A & Chemeo \\
\hline Pinene & Insoluble & 3 & N/A & Chemeo \\
\hline \multicolumn{5}{|c|}{ Herbicides investigated with CYP706A3 } \\
\hline Pendimethalin & 0.3 & 5.2 & -2.24 & $\begin{array}{c}\text { Pubchem } \\
\text { Chemicalbook }\end{array}$ \\
\hline Trifluralin & 0.2 & 5.34 & -1.45 & $\begin{array}{c}\text { Pubchem } \\
\text { Chemicalbook }\end{array}$ \\
\hline Ethalfluralin & 0.3 & 5.11 & -1.76 & $\begin{array}{c}\text { Pubchem } \\
\text { Chemicalbook }\end{array}$ \\
\hline Benefin & 1 & 5.29 & -0.59 & $\begin{array}{c}\text { Pubchem } \\
\text { Chemicalbook }\end{array}$ \\
\hline Oryzalin & 2.5 & 3.73 & 9.4 & $\begin{array}{c}\text { Pubchem } \\
\text { Chemicalbook }\end{array}$ \\
\hline \multicolumn{5}{|c|}{ Natural substrates of CYP76s } \\
\hline Linalool & 1590 & 2.97 & 14.5 & $\begin{array}{c}\text { Pubchem } \\
\text { Chemicalbook }\end{array}$ \\
\hline Geraniol & 100 & 3.56 & 14.4 & $\begin{array}{c}\text { Pubchem } \\
\text { Chemicalbook }\end{array}$ \\
\hline \multicolumn{5}{|c|}{ Herbicide substrates of CYP76s } \\
\hline Chlorotoluron & 70 & 2.41 & 14.43 & $\begin{array}{c}\text { Pubchem } \\
\text { Chemicalbook }\end{array}$ \\
\hline Linuron & 75 & 3.20 & 12.13 & $\begin{array}{c}\text { Pubchem } \\
\text { Chemicalbook }\end{array}$ \\
\hline Isoproturon & 60 & 2.87 & 15.06 & $\begin{array}{c}\text { Pubchem } \\
\text { Chemicalbook }\end{array}$ \\
\hline
\end{tabular}



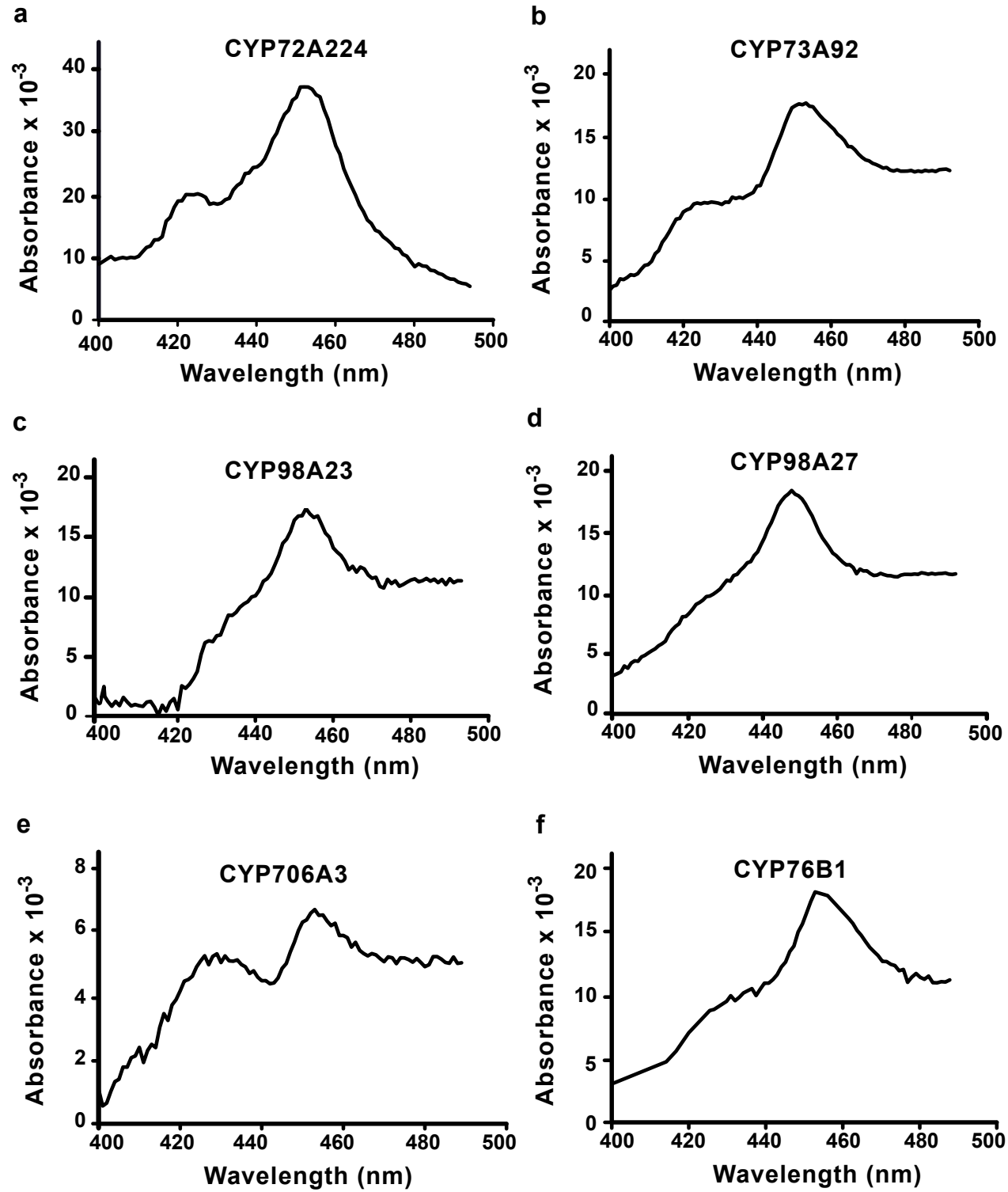

Fig. 1. Carbon monoxide-reduced versus reduced difference spectra of recombinant $\mathbf{P 4 5 0}$ investigated.

$200 \mathrm{ml}$ microsomal membranes were diluted 10 -fold for recording the absorbance of the reduced-CO bound enzyme as described in the Material and Methods section. Absorbance at $450 \mathrm{~nm}$ indicates the presence of functional P450. Absorbance at $420 \mathrm{~nm}$ is indicative of the presence of inactive enzyme (disrupted heme-cysteine bond). 


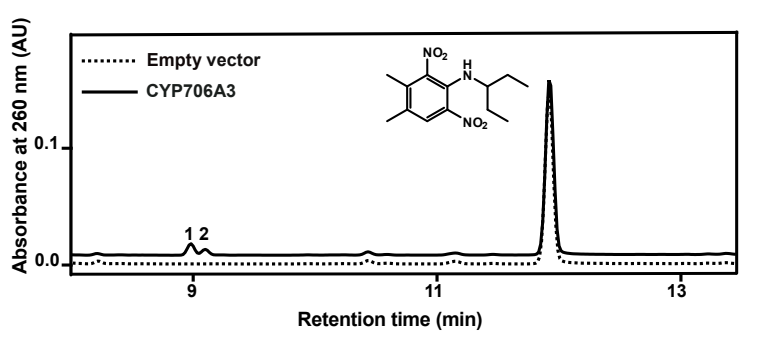

Fig. 2. Conversion of pendimethalin by CYP706A3 in recombinant yeast microsomes.

High performance liquid chromatography with diode array detection (HPLC-DAD) chromatogram of the reaction mixture resulting from the incubation of $100 \mu \mathrm{M}$ pendimethalin with microsomes of yeast transformed with an empty vector or with a vector harboring CYP706A3 for $20 \mathrm{~min}$ in the presence of NADPH (10 $\mu \mathrm{g}$ of P450 in the assay). Based on retention times, peaks $\mathbf{1}$ and $\mathbf{2}$ were identified as potential products. AU: absorbance units. 
a

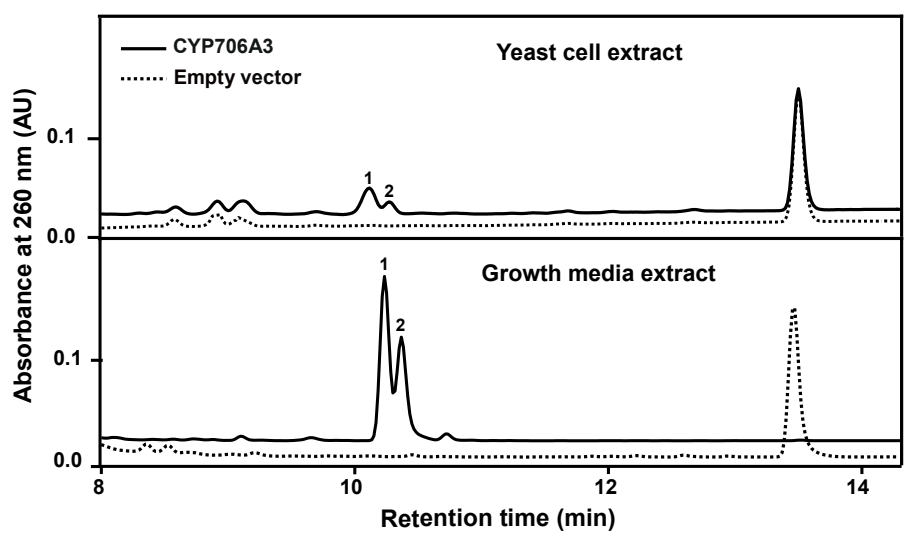

b

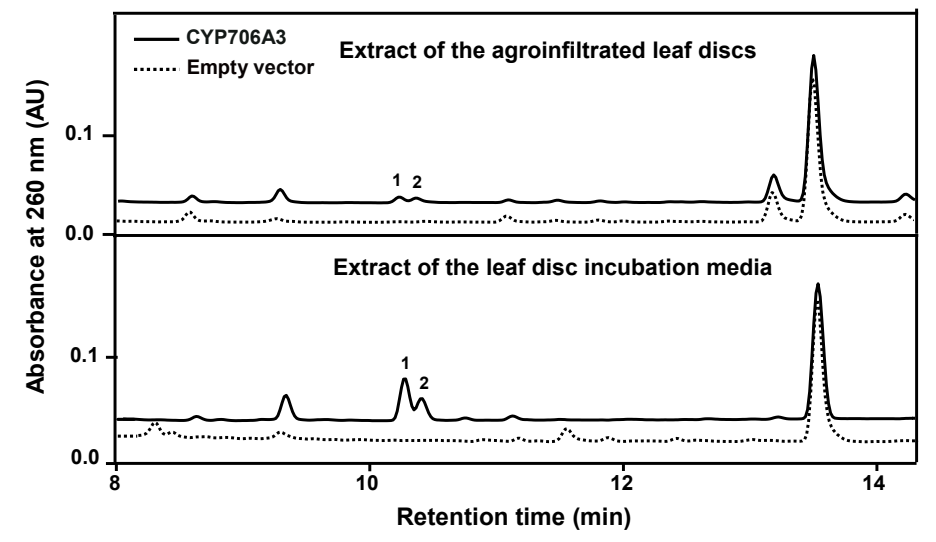

C

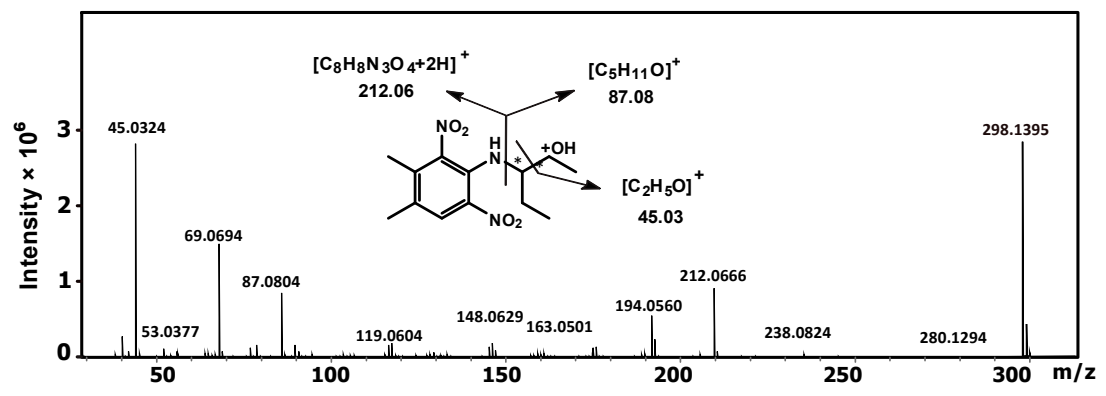

Fig. 3. Pendimethalin conversion by CYP706A3 in whole yeast and Nicotiana benthamiana leaf discs, and mass-coupled liquid chromatography (LC-MS) characterization of the conversion products. a. Whole yeast, transformed with $C Y P 706 A 3-$ harbouring or empty expression vector (empty-control), was grown and CYP706A3 expression was induced as described in the Materials and Methods section. After overnight galactose induction of CYP706A3 expression, $200 \mu \mathrm{M}$ of pendimethalin were added to the medium. Conversion products were extracted after 24 hours further incubation at room temperature, separately from yeast cells and growth medium, and analyzed by high performance chromatography with diode array detection (HPLC-DAD). Peaks $\mathbf{1}$ and $\mathbf{2}$ correspond to the products detected in Fig. 2 . b. $N$. benthamiana leaf discs, transiently expressing CYP706A3 or the empty plant expression vector (EV) control, were incubated in $20 \mathrm{mM} \mathrm{Na}$-phosphate buffer ( $\mathrm{pH}$ 7.4) containing $200 \mu \mathrm{M}$ pendimethalin at $20^{\circ} \mathrm{C}$ under light for $24 \mathrm{~h}$. Methanol-extracts from the leaf-discs or incubation media were separately analyzed by HPLC-DAD. c. Fragmentation patterns of the products of CYP706A3-mediated conversion extracted from whole yeast incubation of pendimethalin. The fragmentation patterns of products $\mathbf{1}$ and $\mathbf{2}$ were identical. Note that pendimethalin hydroxylation on the side-chain generates two chiral carbons. 

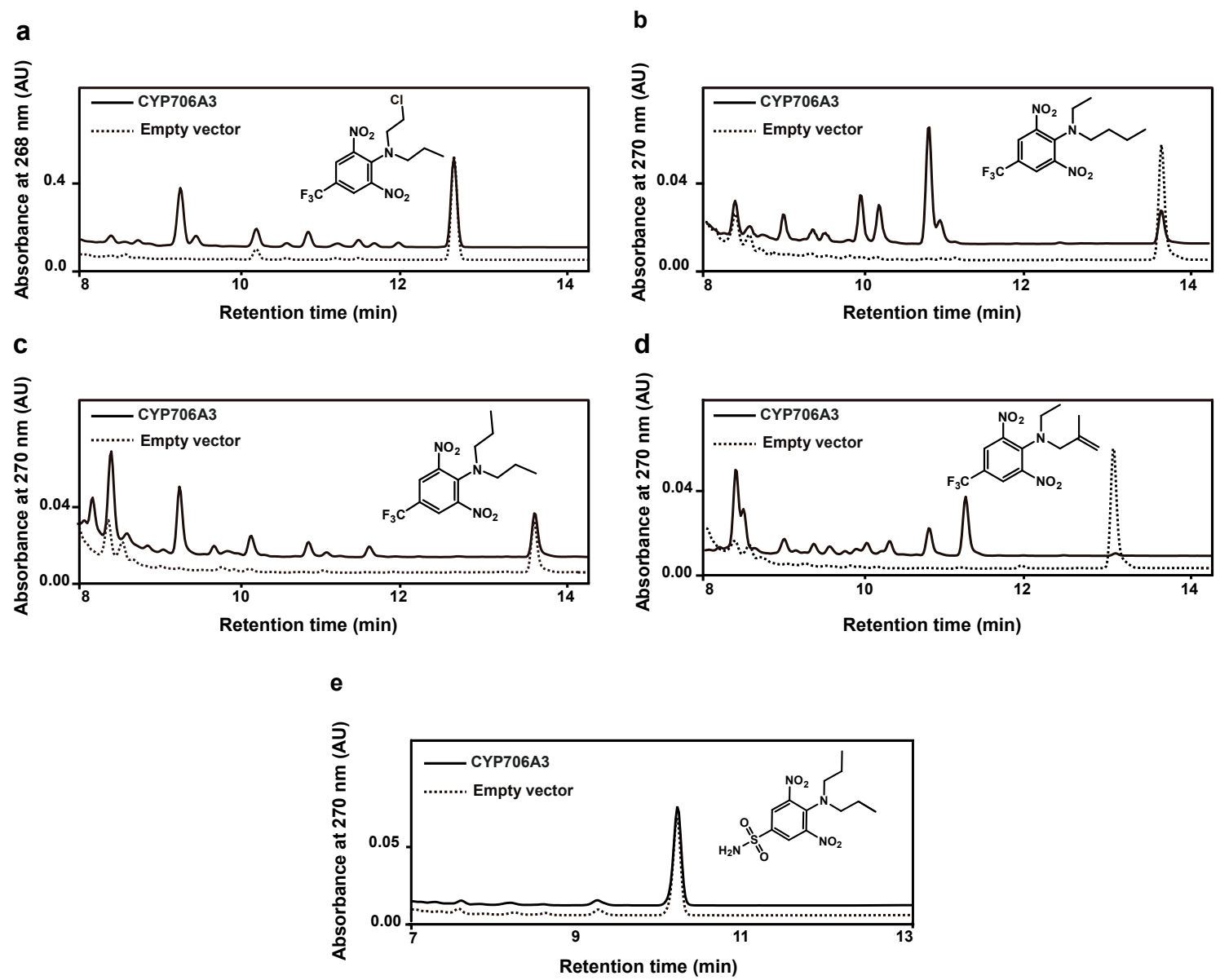

Fig. 4. CYP706A3-mediated dinitroaniline conversion in whole yeast assay. CYP706A3- or empty vectortransformed whole yeast cultures were incubated with $200 \mu \mathrm{M}$ of herbicide for 24 hours at $20^{\circ} \mathrm{C}$. a. Fluchloralin; b. Benefin; c. Trifluralin; d. Ethalfluralin; e. Oryzalin. 


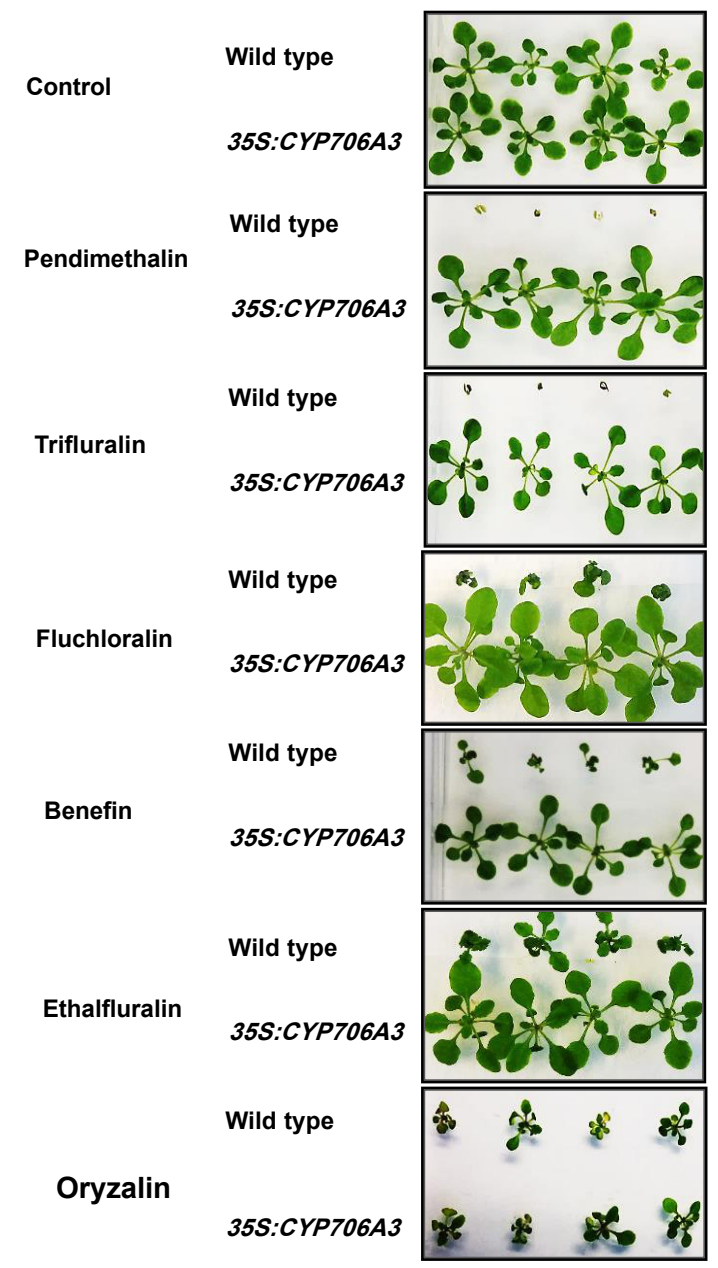

Fig. 5. Arabidopsis thaliana ectopically expressing CYP706A3 is tolerant to dinitroanilines. Fifteen days-old seedlings were further grown for 14 days in the presence or absence of $1 \mu \mathrm{M}$ of dinitroanilines. 


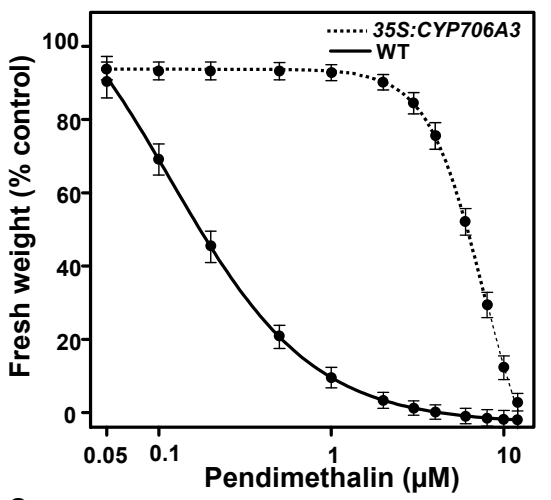

c
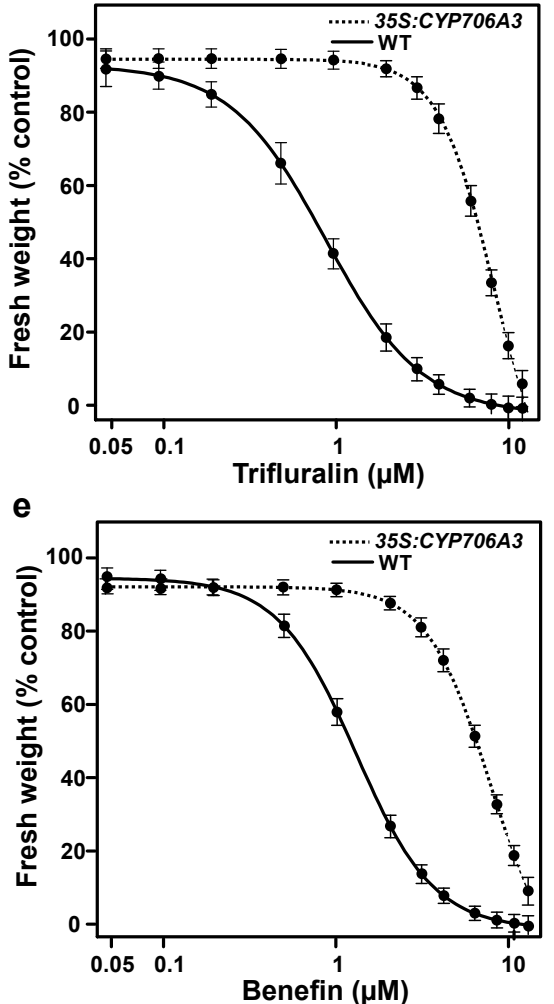

b

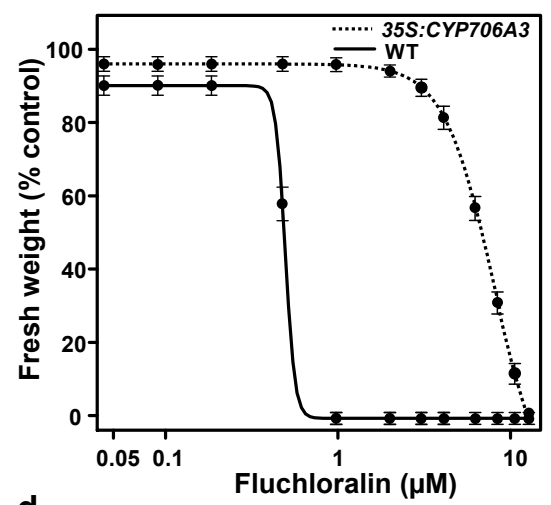

d

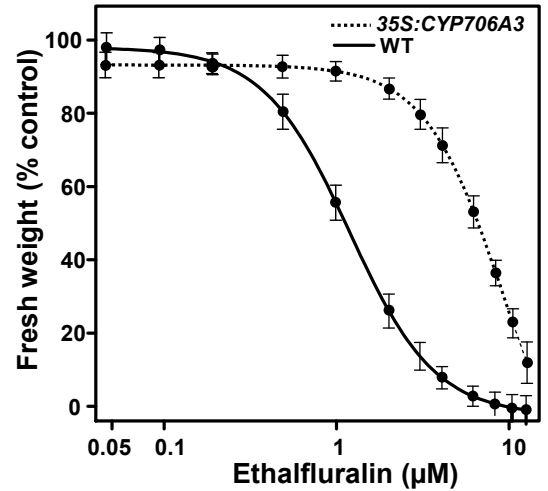

f

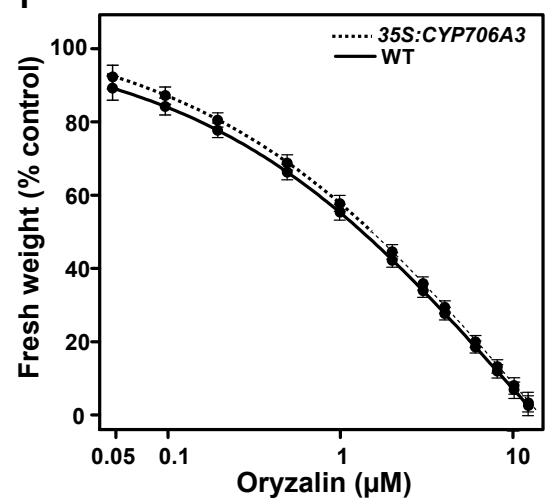

Figure 6. Dose response of the A. thaliana 35S:CYP706A3 overexpressing line (35S:CYP706A3) to pendimethalin (a), fluchloralin (b), trifluralin (c), ethalfluralin (d), benefin (e) and oryzalin (f) in comparison with the wild type (WT) control. Plants were grown during 15 days on MS medium either in the presence or absence of different concentrations of herbicides. 
a

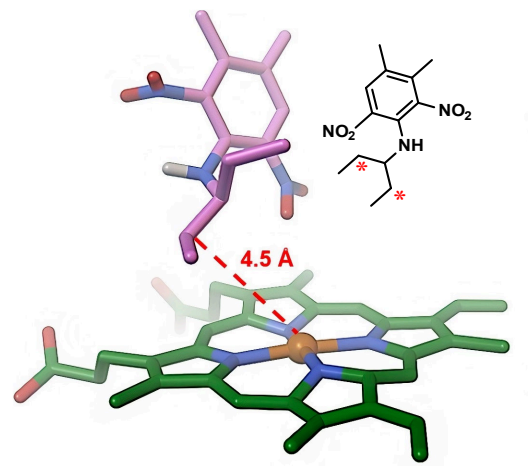

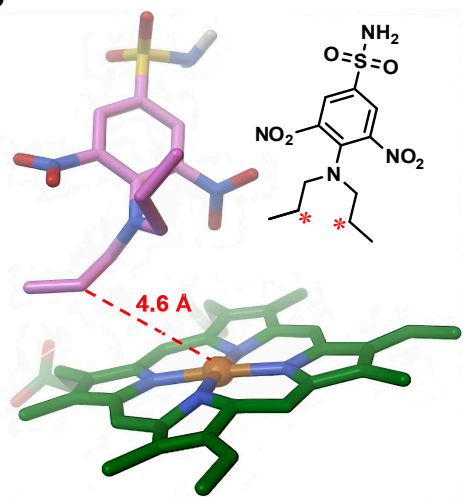

Figure 7. Binding mode of dinitroanilines pendimethalin and oryzalin in $\mathrm{CYP706A3}$ active site.

Docking experiments were performed with Autodock Smina (using Vina scoring function) on the rebuilt 3D model of CYP706A3. Heme cofactor is represented in green sticks with iron atom sphere in orange, and ligands are represented in sticks in atom color mode. In both ligands poses, the carbon atom nearest to the heme iron is the subterminal $\mathrm{CH} 2$ group of alkyl chain. Distances are indicated in Angstroms. In insert is displayed the molecular sketch with predicted positions of metabolism indicated by a red mark. a.Best docking pose of pendimethalin, with binding energy of $-7.4 \mathrm{kcal} . \mathrm{mol}^{-1}$. b. Best docking pose of oryzalin with binding energy of $-6.6 \mathrm{kcal}^{\mathrm{mol}}{ }^{-1}$. 

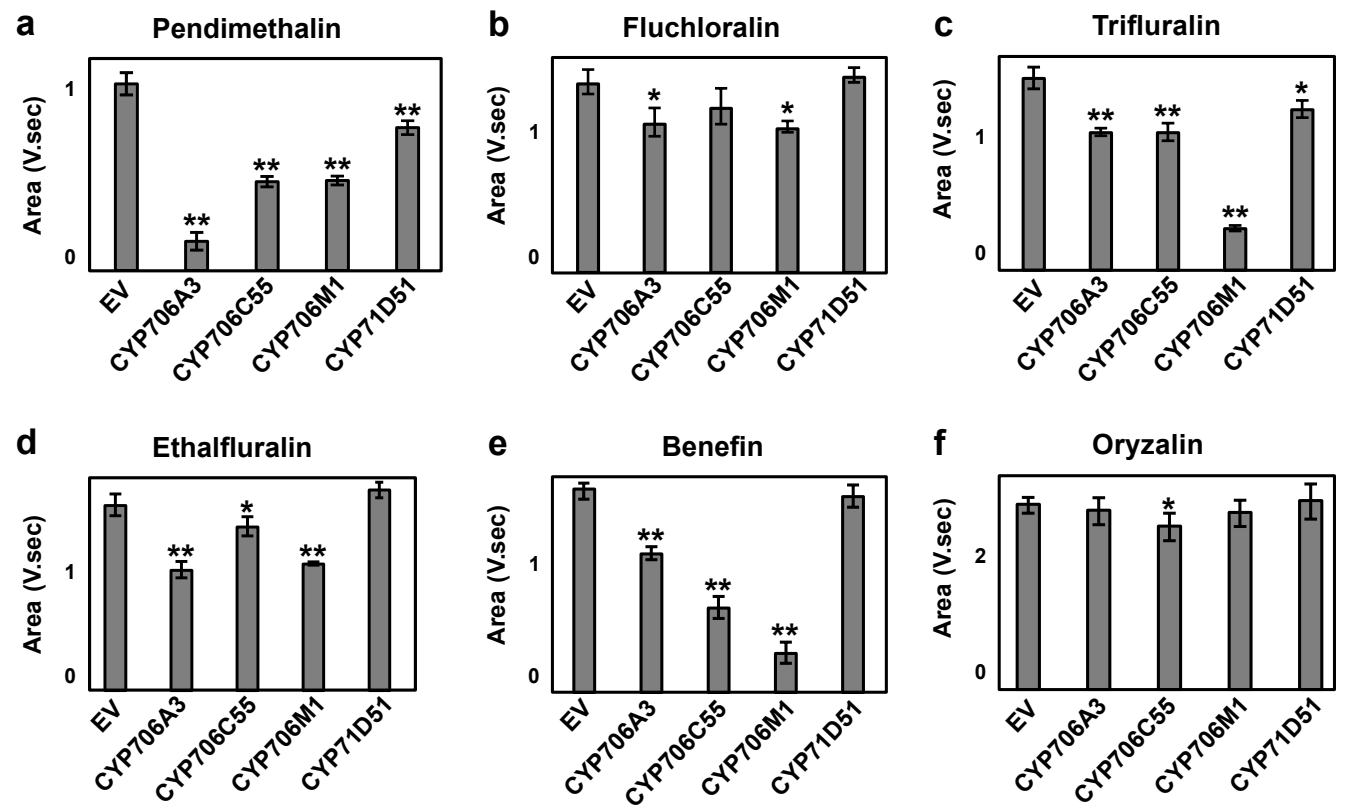

Figure 8. Dinitroaniline conversion by other sesquiterpene-metabolizing enzymes.

Five $\mathrm{ml}$ cultures of empty vector- or P450-transformed yeasts were incubated in $20 \mathrm{ml}$ tubes with $200 \mu \mathrm{M}$ of herbicide for 24 hours at $20^{\circ} \mathrm{C}$ with shaking at $180 \mathrm{rpm}$. Culture supernatant was collected after centrifugation at 4,500 rpm for $15 \mathrm{~min}$ and directly injected for high performance chromatography with diode array detection. Residual herbicide was evaluated from the herbicide peak area. Data shown are means \pm SD of three replicates. Statistically significant differences between empty vector control and P450-transformed yeasts are indicated by stars (Student's t- test: ${ }^{*} \mathrm{p}<0.05 ;{ }^{* *} \mathrm{p}<0.01$ ). 


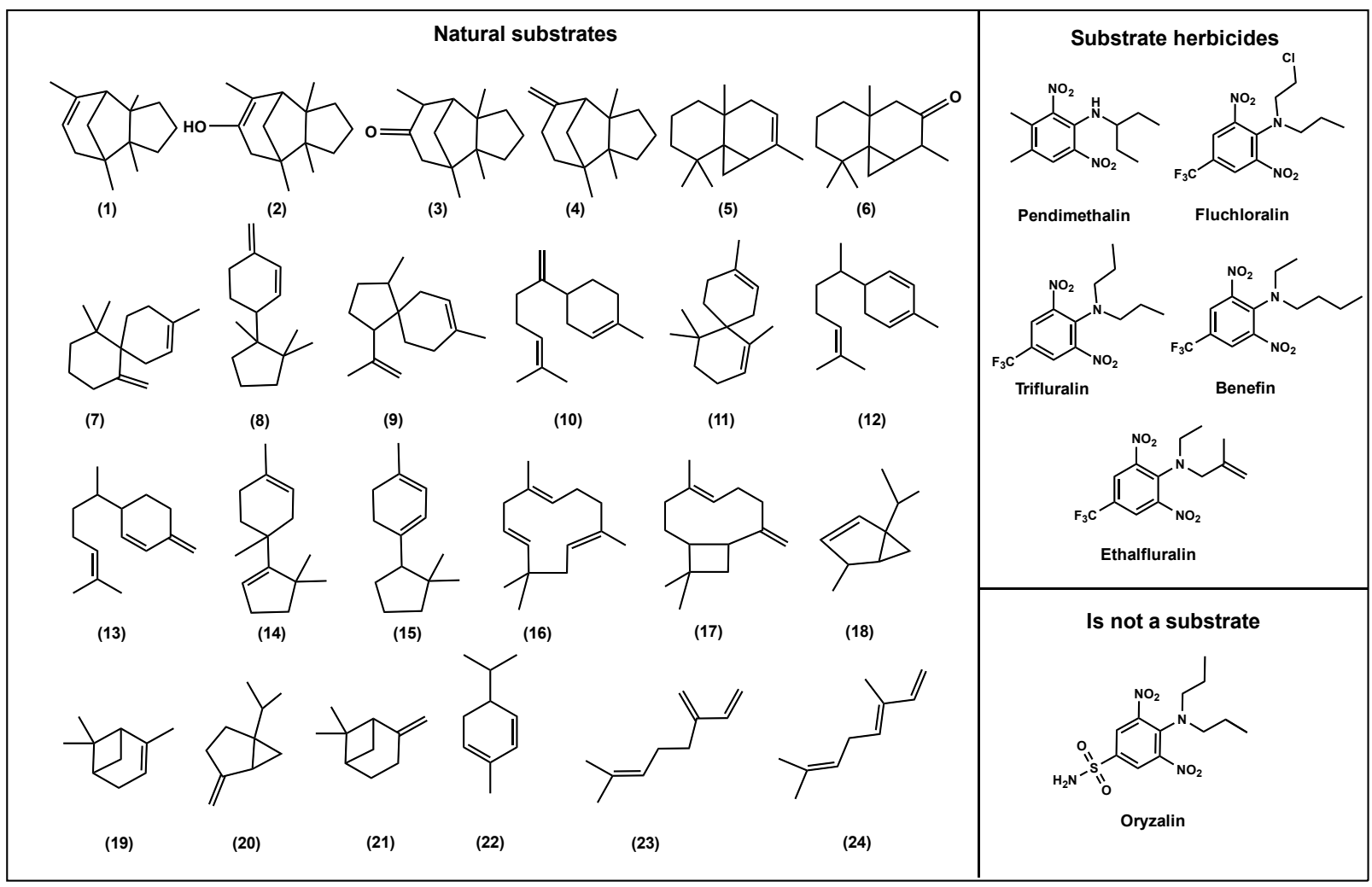

Fig. 9. Chemical structures of the natural and herbicide substrates of CYP706A3 compared to oryzalin. Sesquiterpenes: (+)- $\alpha$-barbatene (1), (+)- $\beta$-barbatene (4), (+)-thujopsene (6), (+)- $\beta$-chamigrene (7), $\sigma$ cuprenene (8), $\beta$-acoradiene (9), (E)- $\gamma$-bisabolene (10), (+)- $\alpha$-chamigrene (11), $\alpha$-zingiberene (12), $\beta$ sesquiphellandrene (13), isobazzanene (14), $\alpha$-cuprenene (15), $\alpha$-humulene (16), (-)-(E)- $\beta$-caryophylene (17). Monoterpenes: $\beta$-thujene (18), $\alpha$-pinene (19), $(+)$-sabinene (20), $\beta$-pinene (21), $\alpha$-phellandrene (22), $\beta$ myrcene (23), $\beta$-cis-ocimene (24). Oxygenated derivatives: $(+)-6-\mathrm{OH}-\alpha$-barbatene $(2),(+)-6$-oxo-barbatene (3), (+)-1-oxo-thujopsene (5). 


\section{Supporting information}

Fig. S1 Optimization of the incubation time for the production of CYP706A3 oxidation products in the whole yeast culture. Yeasts expressing $C Y P 706 A 3$ or the empty expression vector (emptycontrol) were incubated with $200 \mu \mathrm{M}$ of pendimethalin for 2 to 24 hours at room temperature. Pendimethalin conversion was evaluated by high pressure liquid chromatography coupled to diode array detection.

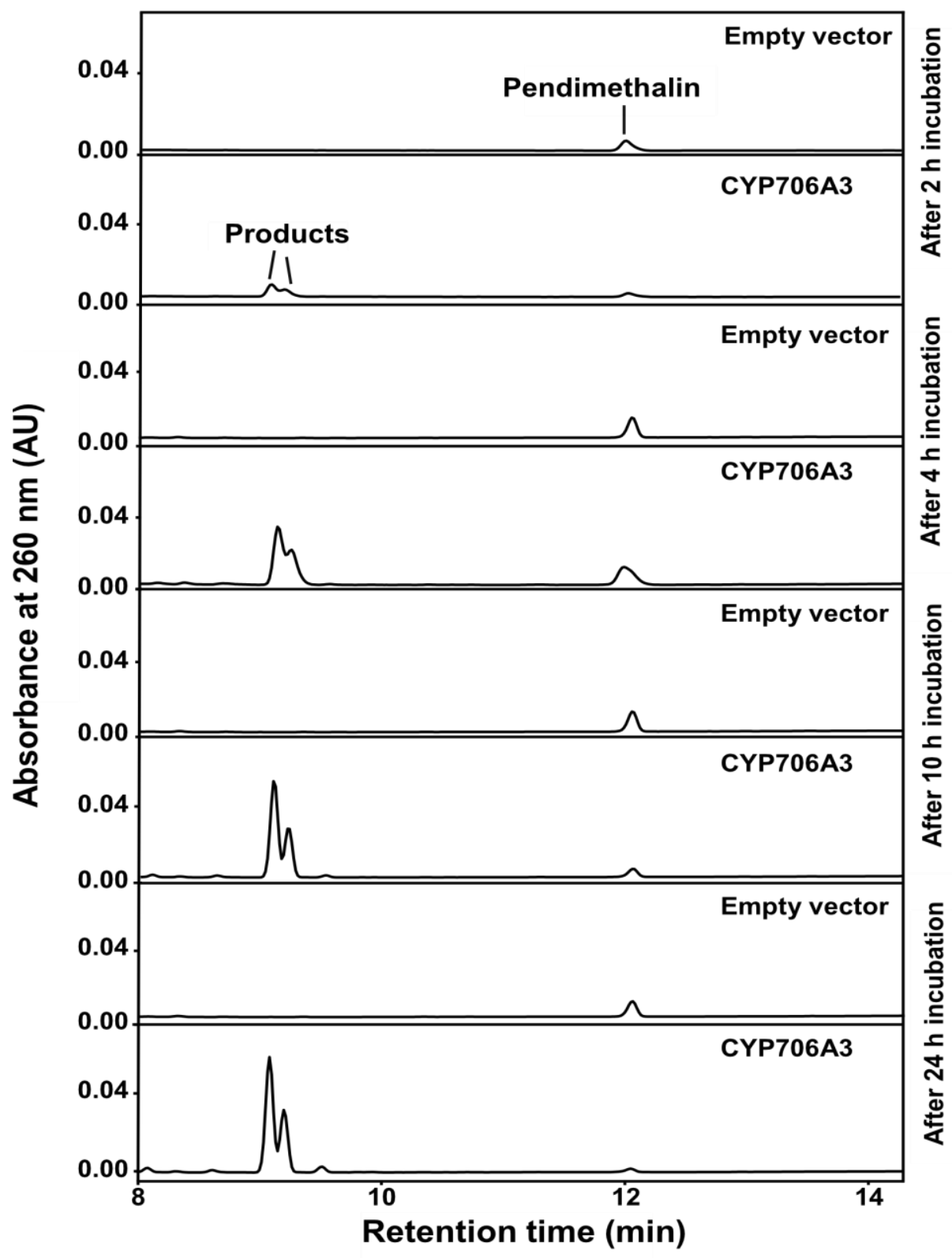


Fig. S2 Liquid chromatography mass spectrometry profiling of the pendimethalin conversion products of CYP706A3. a. Extracted ion chromatogram of products $\left(\mathrm{C}_{13} \mathrm{H}_{19} \mathrm{~N}_{3} \mathrm{O}_{5},[\mathrm{M}+\mathrm{H}]^{+}\right) \mathbf{b}$. Extracted ion chromatogram of pendimethalin $\left(\mathrm{C}_{13} \mathrm{H}_{19} \mathrm{~N}_{3} \mathrm{O}_{4},[\mathrm{M}+\mathrm{H}]^{+}\right)$.

a

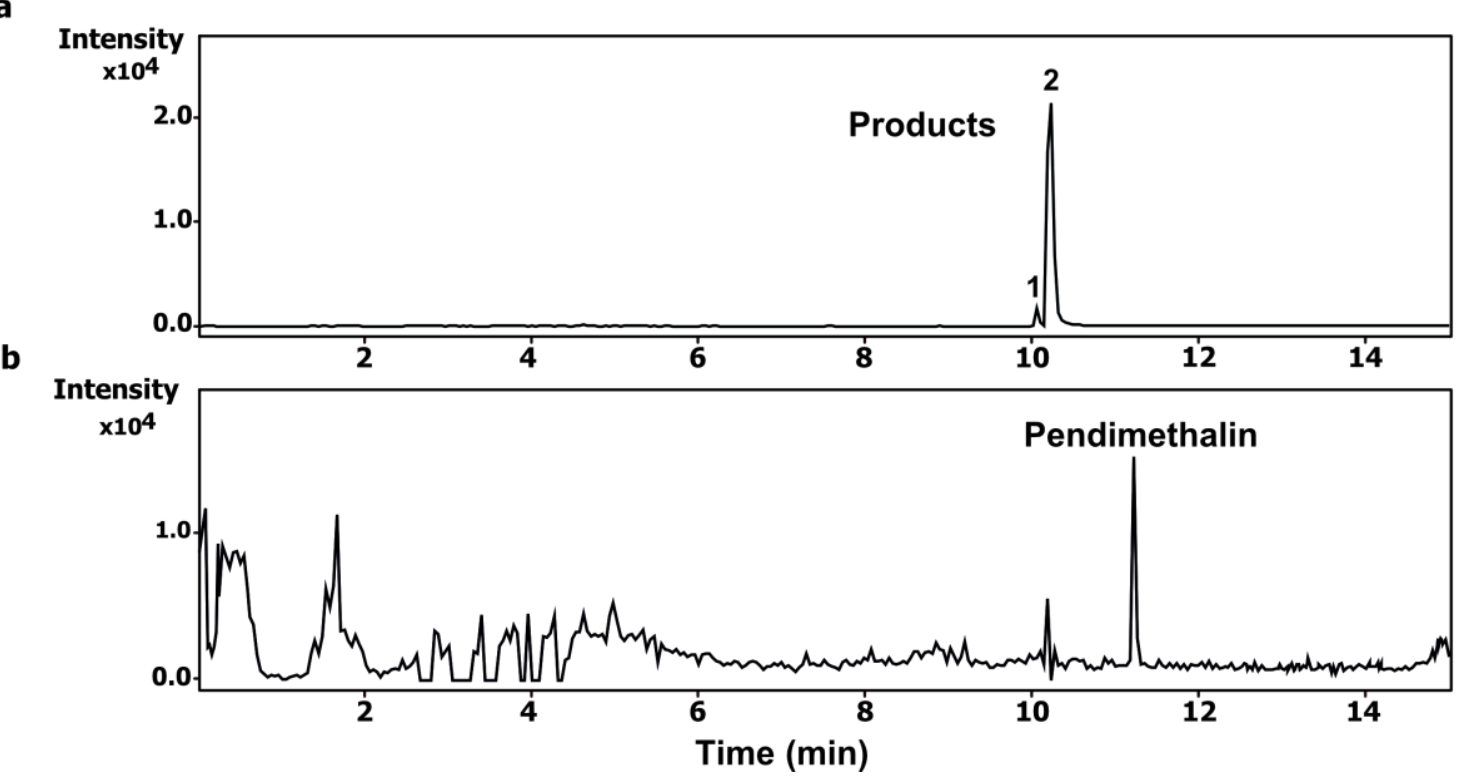


Fig. S3 Nuclear magnetic resonance (NMR) characterization of the pendimethalin oxidation products. a.Thin-layer chromatography (TLC) separation and purification of the pendimethalin metabolites. Plates were developed and revealed as described in the Materials and Methods section. b. ${ }^{1} \mathrm{H}$-NMR and ${ }^{13} \mathrm{C}$-NMR spectra of diastereoisomer1. c. ${ }^{1} \mathrm{H}-\mathrm{NMR}$ and ${ }^{13} \mathrm{C}$-NMR spectra of diastereoisomer2. NMR determination is provided in Supporting Information Note 3.

a

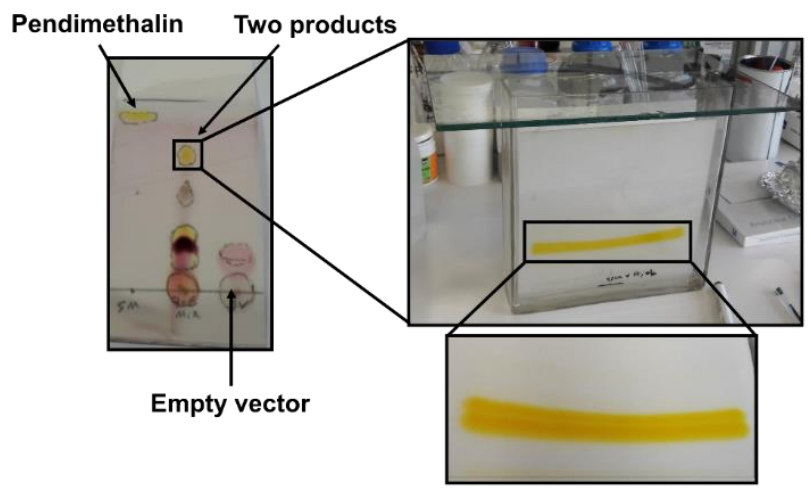

b

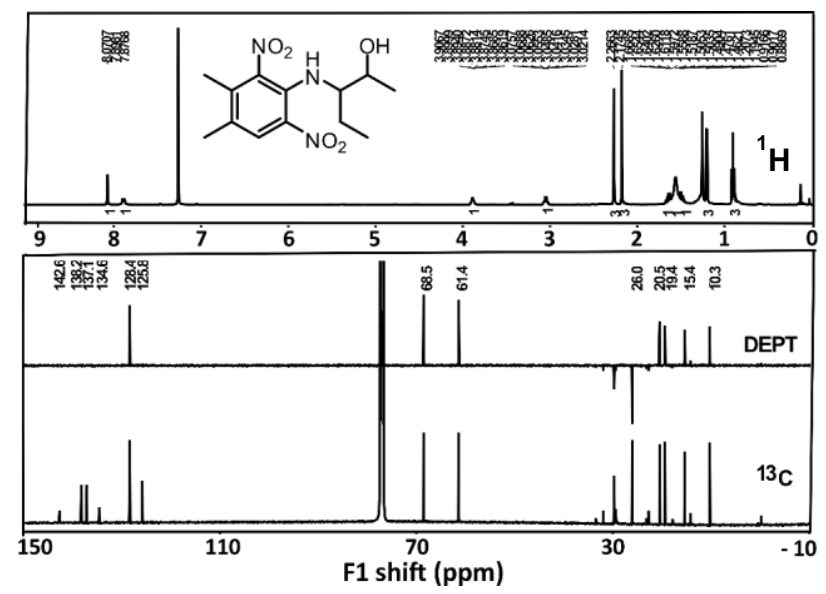

C
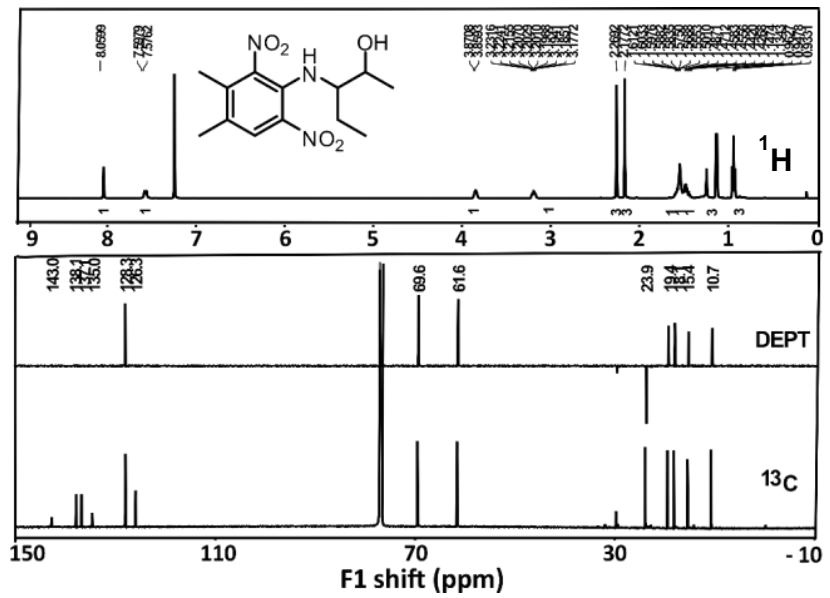
Fig. S4 The thin layer chromatography (TLC)-purified products correspond to the peak 1 and 2 detected by high pressure liquid chromatography coupled to diode array detection (HPLC-DAD) and liquid chromatography coupled to mass spectrometry. The two TLC-purified products were injected separately a and b) and as a mix (c) on HPLC-DAD, and compared to the extract of a whole yeast culture (d). e. Mix of whole yeast culture and purified products.

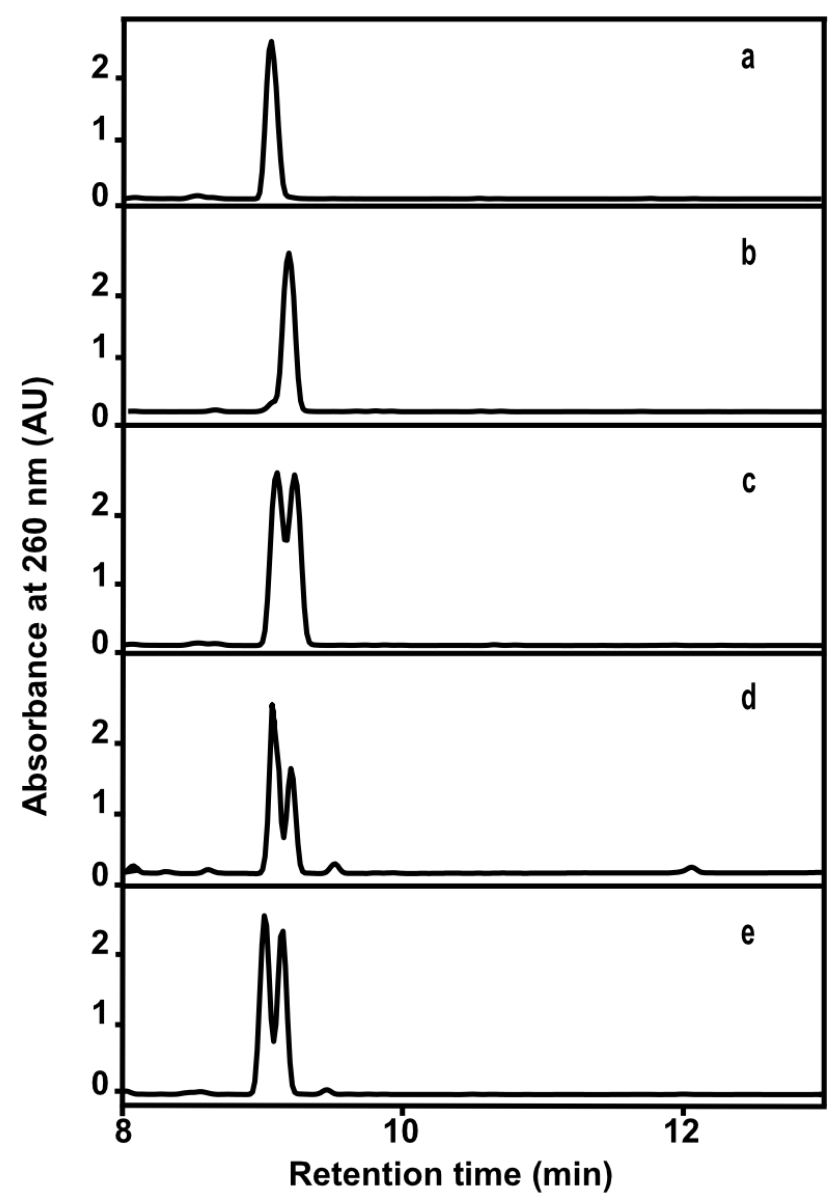


Fig. S5 Saturation curve based on Michaelis-Menten non-linear regression used to calculate affinity constant and turnover of CYP706A3 with pendimethalin.

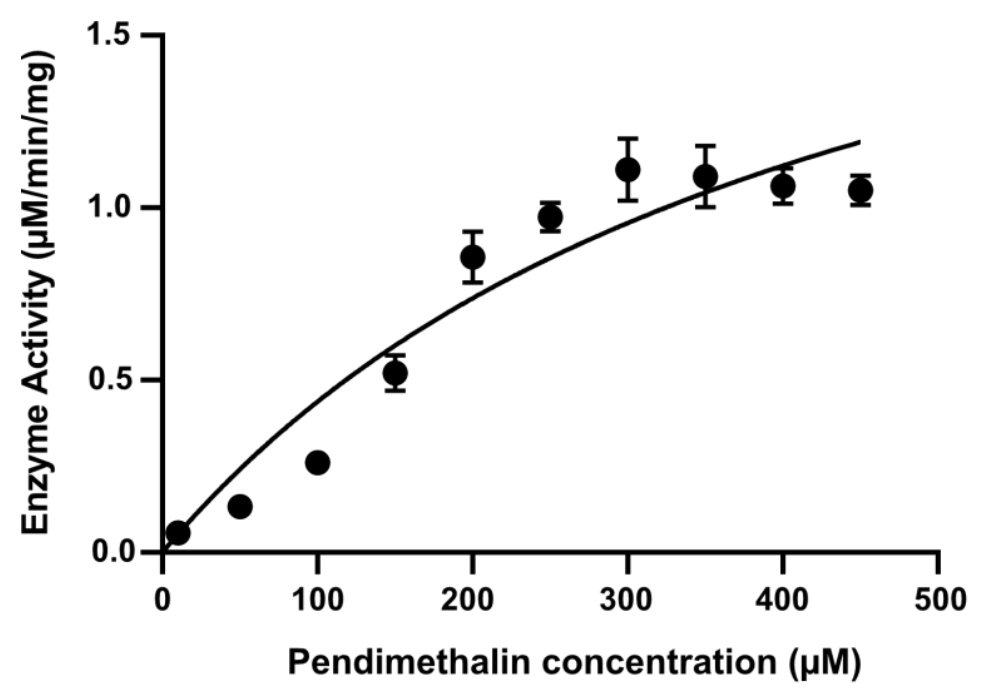


Fig. S6 Extracted ion chromatograms corresponding to $\mathrm{m} / \mathrm{z}$ of dinitroaniline active ingredients $(\mathrm{M}+1)$ (when detectable) and oxygenated conversion products $(\mathrm{M}+16, \mathrm{M}+32)$ resulting from tested P450-dependent conversion. a. Pendimethalin $(\mathrm{m} / \mathrm{z}=182)$, oxidized $(\mathrm{m} / \mathrm{z}=298)$ and twice oxidized $(\mathrm{m} / \mathrm{z}=314)$. b. Fluchloralin $(\mathrm{m} / \mathrm{z}=356)$, oxidized $(\mathrm{m} / \mathrm{z}=372)$ and twice oxidized $(\mathrm{m} / \mathrm{z}=398)$. C. Benefin, trifluralin and ethalfluralin. Only single-oxidized derivatives $(\mathrm{M}+16)$ were detected, with $\mathrm{m} / \mathrm{z}$ corresponding to 352,352 and 349 , respectively for benefin, trifluralin and ethalfluralin. Data were acquired using Acquity UPLC system (Waters) coupled to a Quattro Premier XE mass spectrometer (Waters) equipped with an electrospray ionization source and an Acquity UPLC BEH C18 (100 32.1 mm, $1.7 \mu \mathrm{m}$; Waters) column and precolumn. The mobile phase consisted of (A) water and (B) methanol, both containing $0.1 \%$ formic acid. The run began with 2 min of 95\% A. Then a linear gradient was applied to reach 100\% B at 12 min, followed by an isocratic run using $100 \% \mathrm{~B}$ for $1 \mathrm{~min}$. Return to initial conditions was achieved in 2 min, with a total run time of $17 \mathrm{~min}$. The column was operated at $35^{\circ} \mathrm{C}$ with a flow rate of $0.35 \mathrm{ml} / \mathrm{min}$, injecting $0.05 \mathrm{ml}$ samples. Nitrogen was used as the drying and nebulizing gas. The nebulizer gas flow was set to $50 \mathrm{l} / \mathrm{h}$ and the desolvation gas flow to $900 \mathrm{l} / \mathrm{h}$. The interface temperature was set at $400^{\circ} \mathrm{C}$ and the source temperature at $135^{\circ} \mathrm{C}$. The capillary voltage was set to $3.4 \mathrm{kV}$ and the cone voltage to $25 \mathrm{~V}$; the ionization was in positive mode. For qualitative analysis and mass spectra determination, samples were analyzed with full scan in positive mode, with an energy cone of +25 $\mathrm{V}$ on a range of 100 to $600 \mathrm{~m} / \mathrm{z}$ and with a $0.4-\mathrm{s}$ scan time. Data acquisition and analyses were performed with MassLynx and QuanLynx software version 4.1 (Waters). 


\section{a Pendimethalin}

$m / z=298(M+16)$
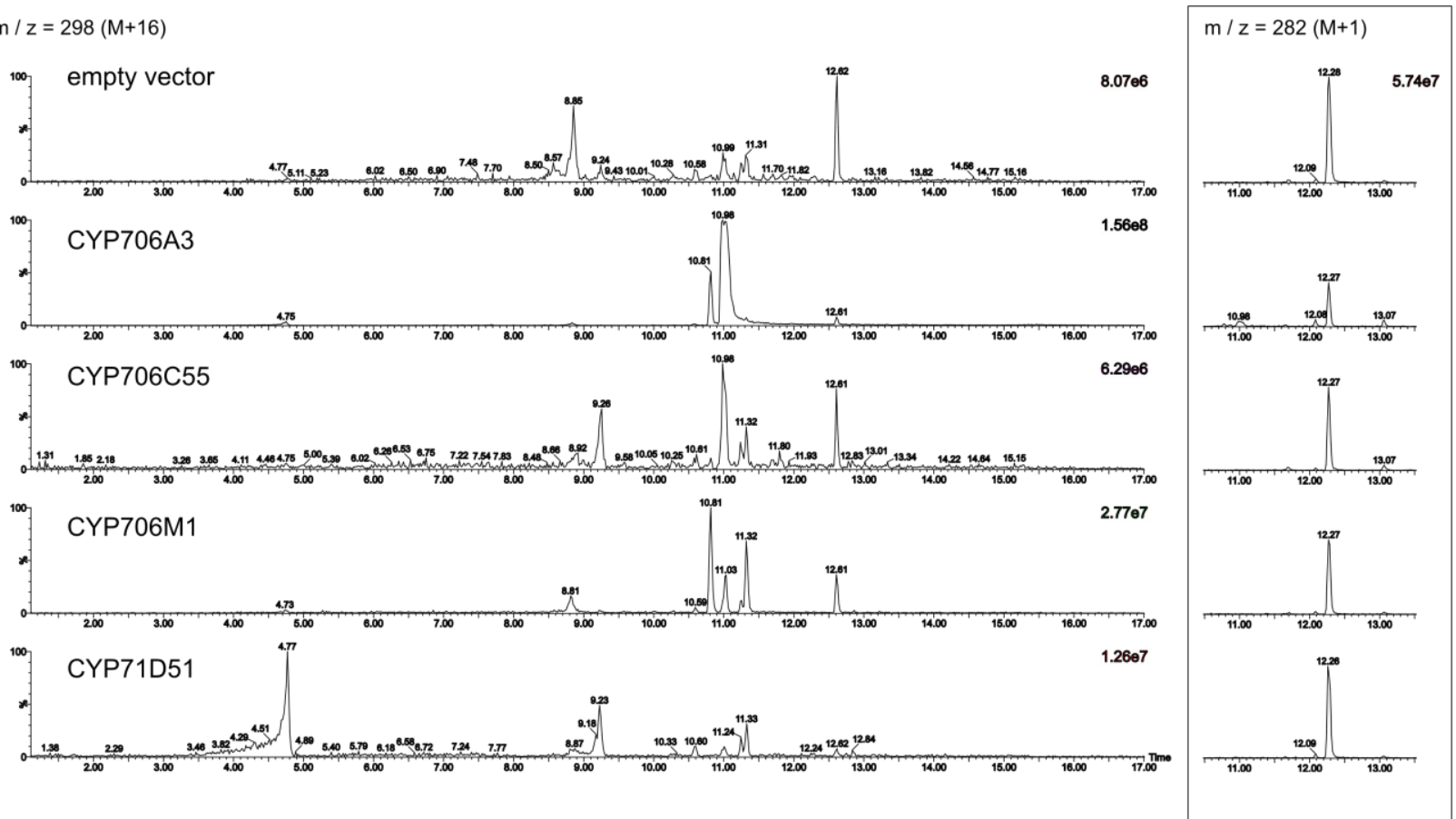

$m / z=314(M+32)$

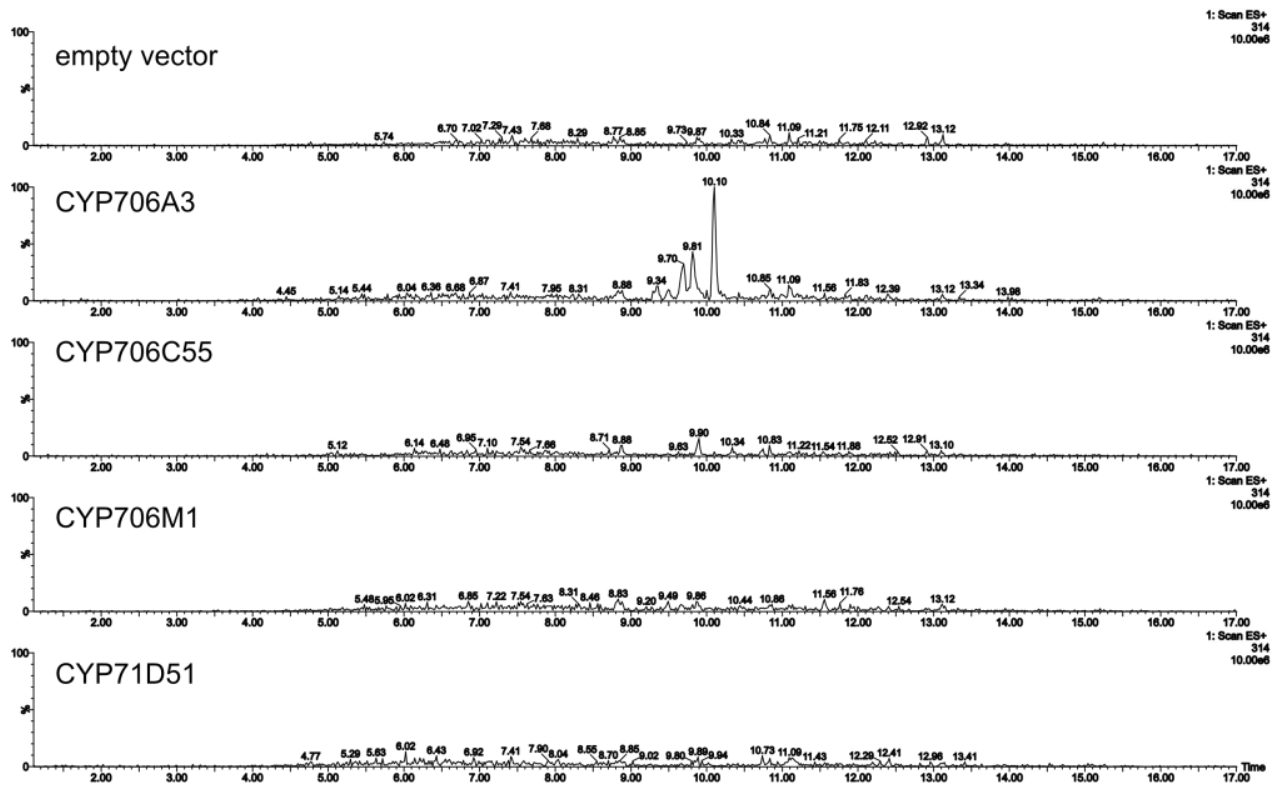


b Fluchloralin

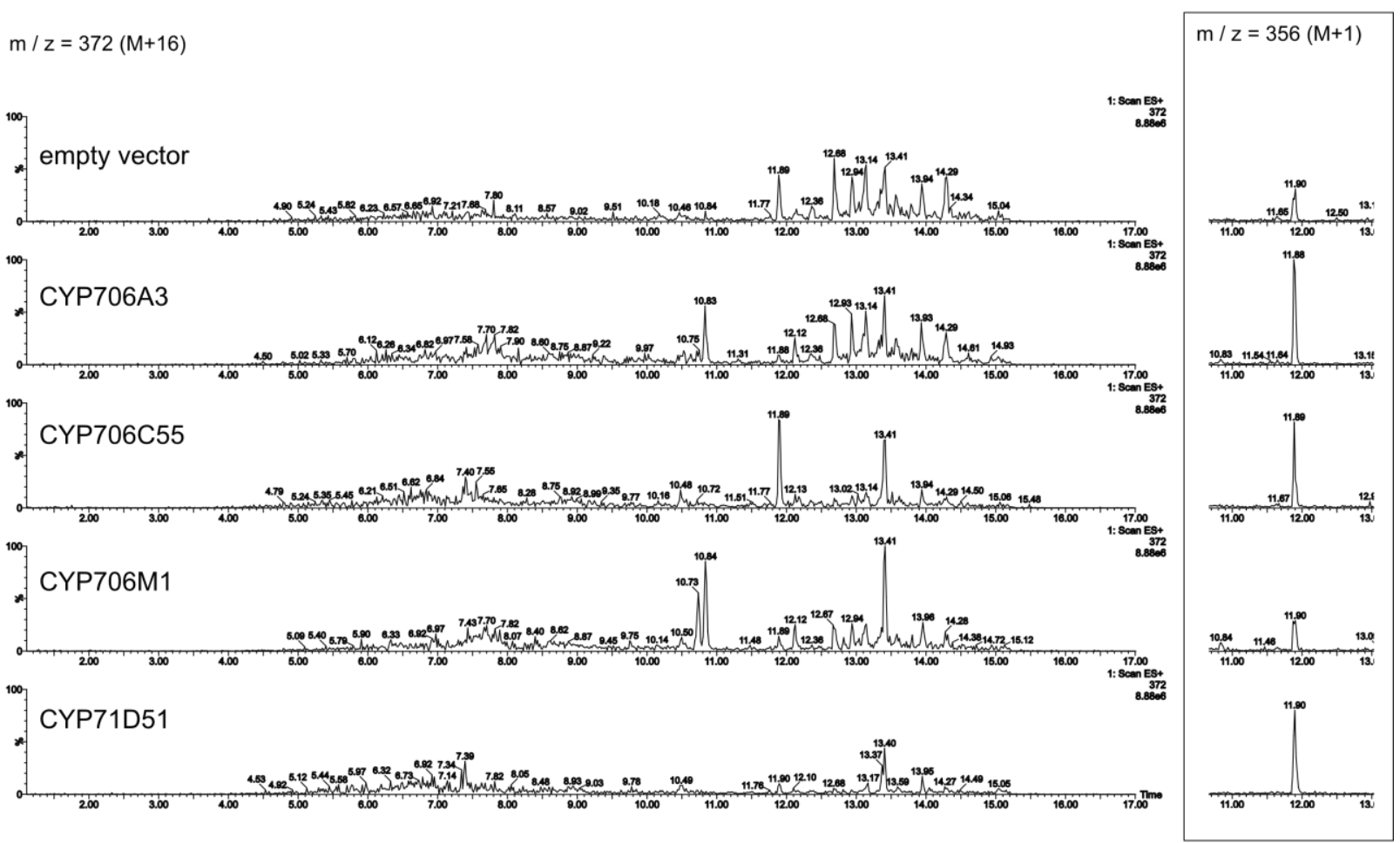

$m / z=398(M+32)$
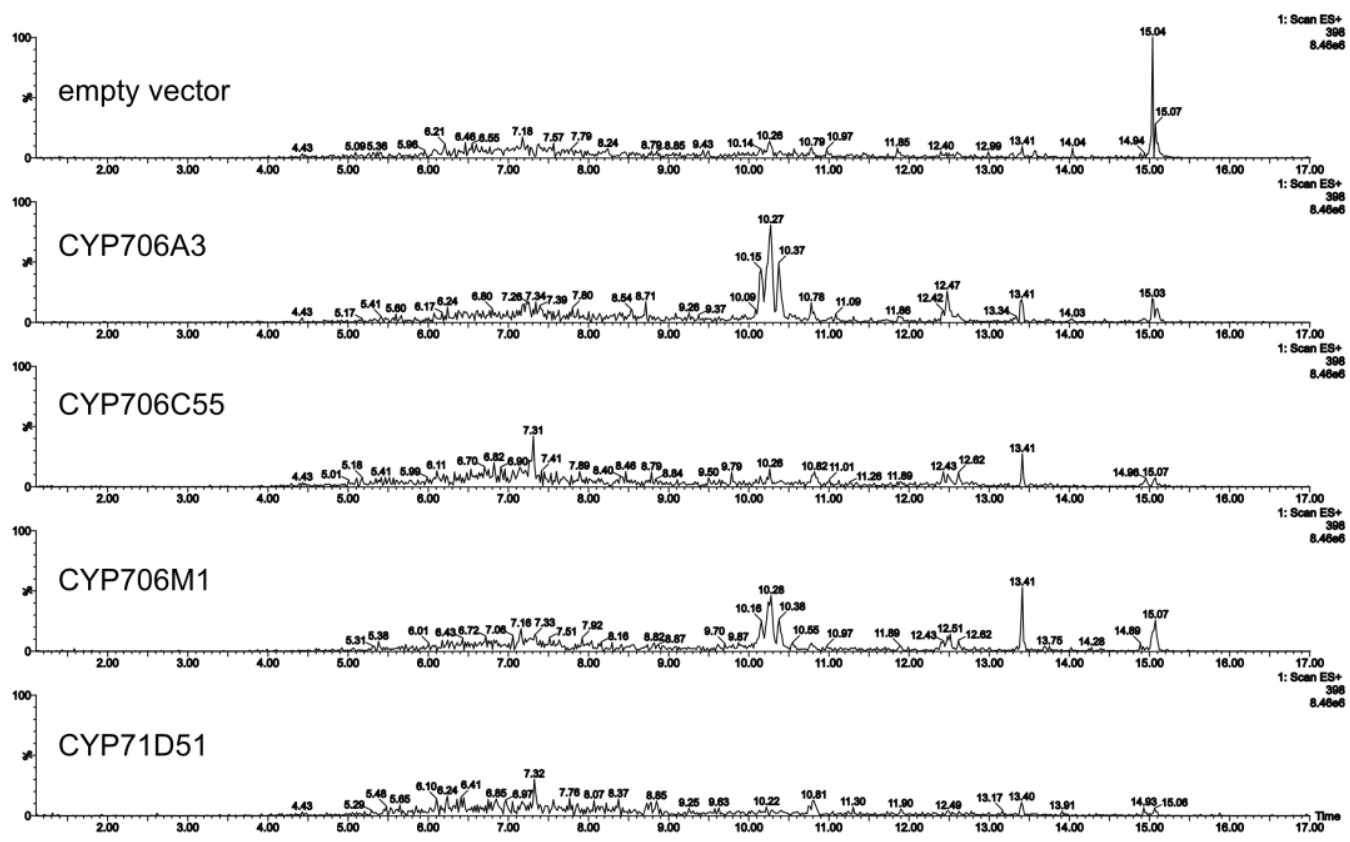


\section{Benefin}

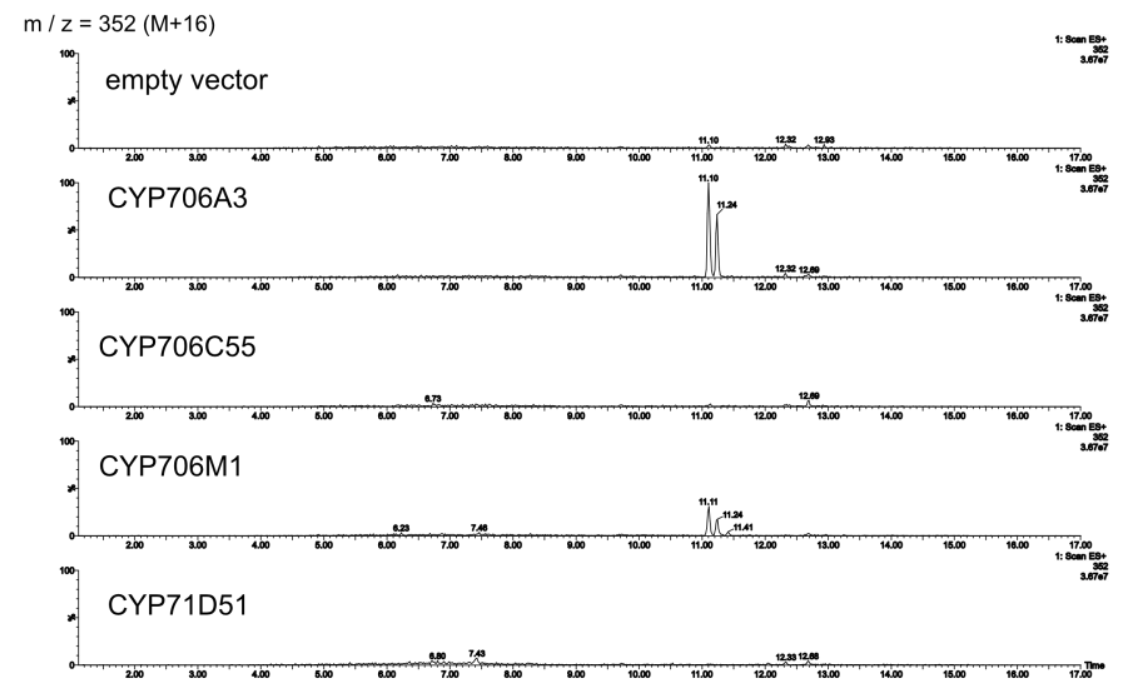

Trifluralin

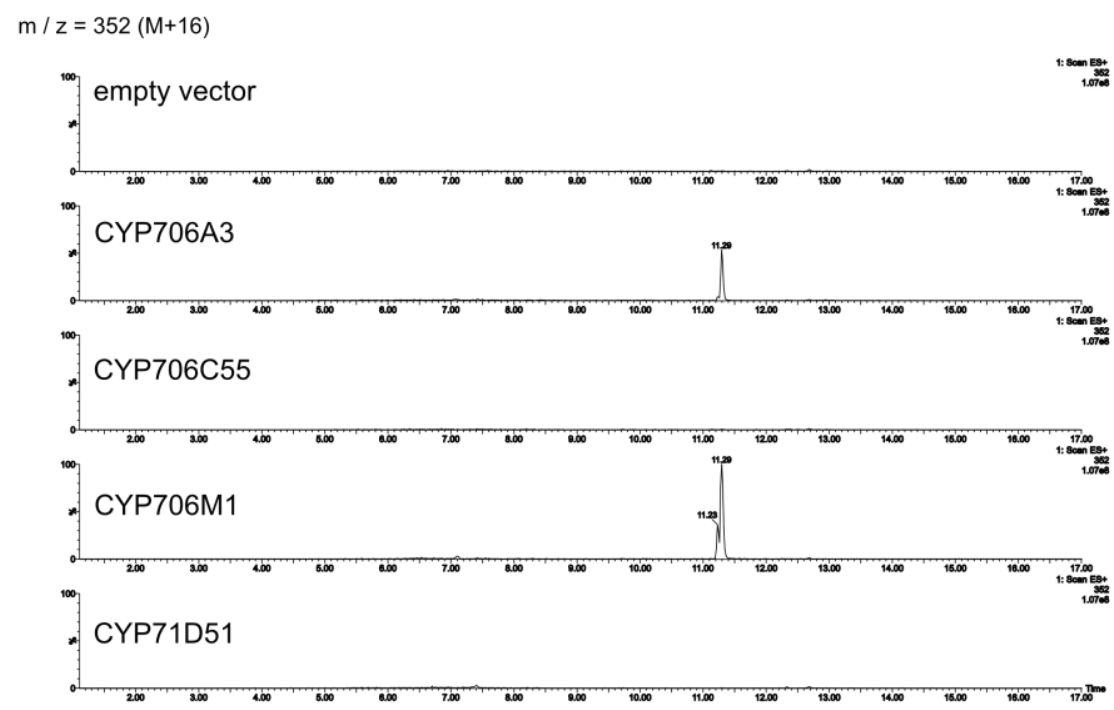

Ethalfluralin

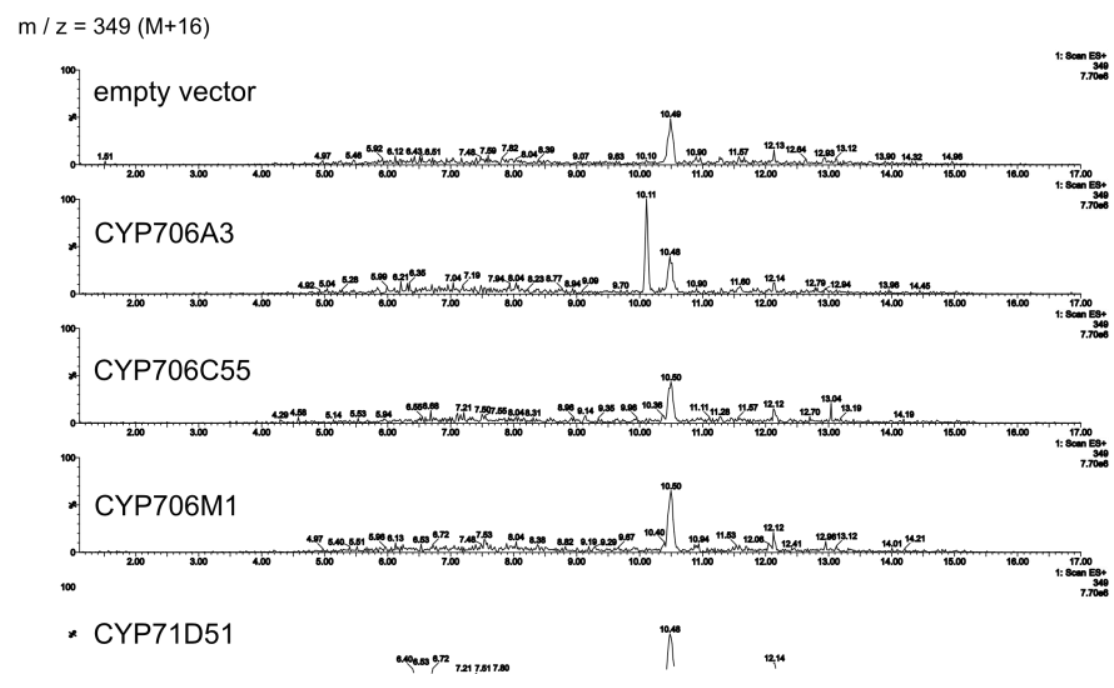


Fig. S7 Tolerance to pendimethalin of $A$. thaliana cyp706a3 null mutants and of bar and CYP73A94 expressing plants. Fifteen days-old seedlings were further grown for 14 days in the presence or absence of $1 \mu \mathrm{M}$ of pendimethalin.

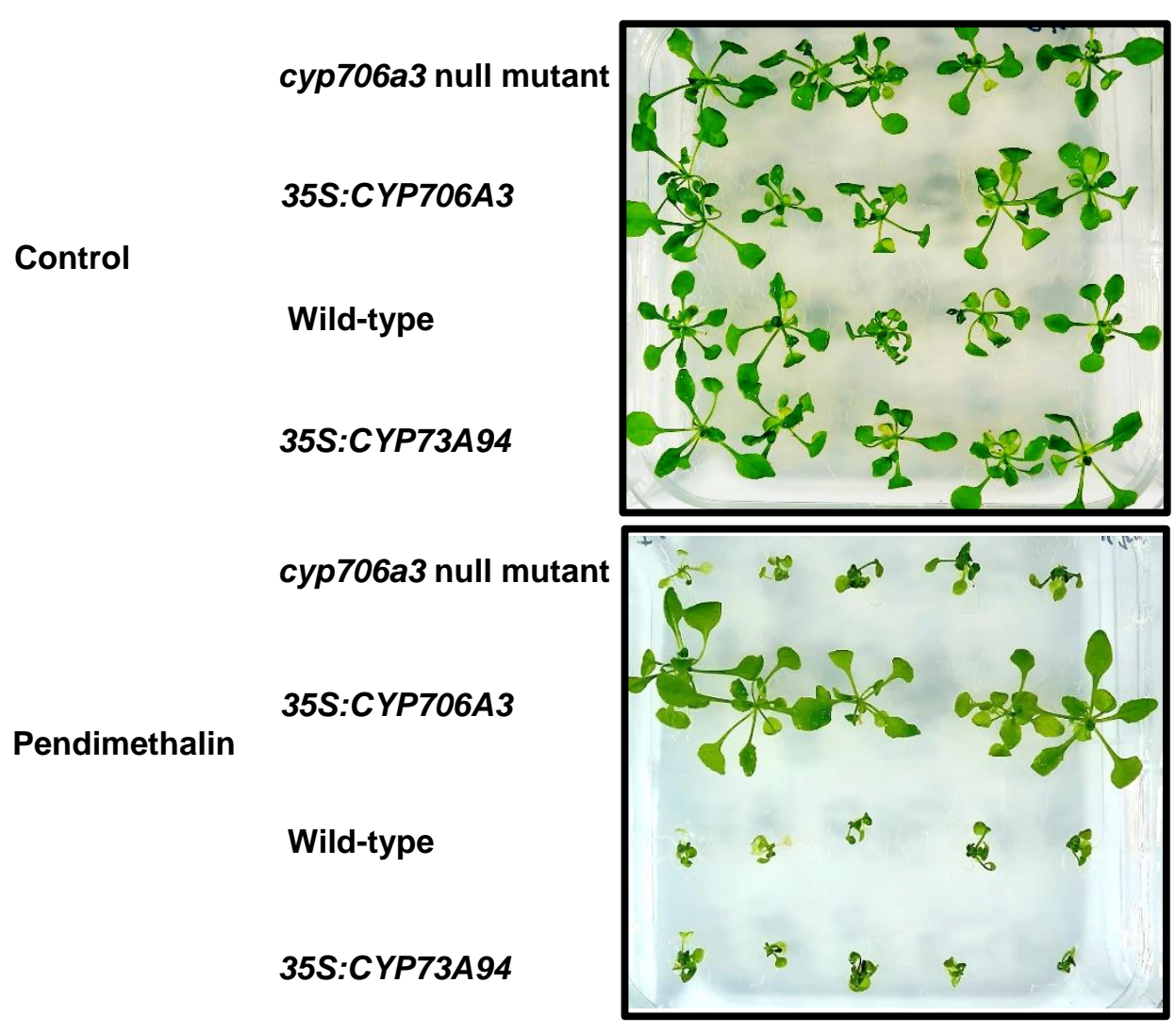


Fig. S8 Binding mode of other dinitroanilines in CYP706A3 active site. Docking experiments were performed with Autodock Smina (using Vina scoring function) on the rebuilt 3D model of CYP706A3. Distances of the substrate carbon atoms nearest to the heme iron are displayed in dotted lines and given in Angstroms. All other representation details are as in legend of Figure 10. a. Best docking pose of benefin, with binding energy of $-7.4 \mathrm{kcal}^{\mathrm{mol}}{ }^{-1}$. b. Best docking pose of ethalfluralin with binding energy of $-7.7 \mathrm{kcal}^{\mathrm{mol}}{ }^{-1}$. In this ligand, two positions of metabolism are predicted. c. Best docking pose of trifluralin with binding energy of $-7.5 \mathrm{kcal} . \mathrm{mol}^{-1}$. d. Best docking pose of fluchloralin with binding energy of $-7.2 \mathrm{kcal}^{\mathrm{mol}}{ }^{-1}$.

a
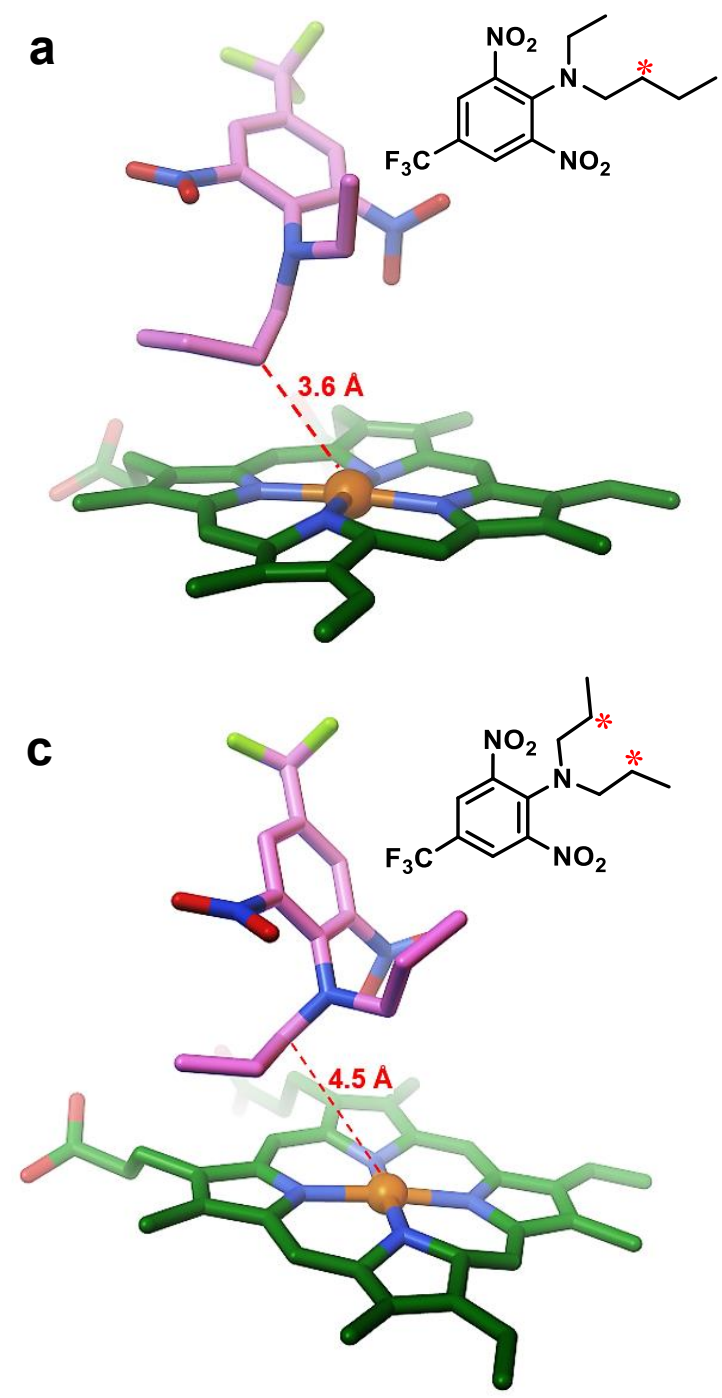

b

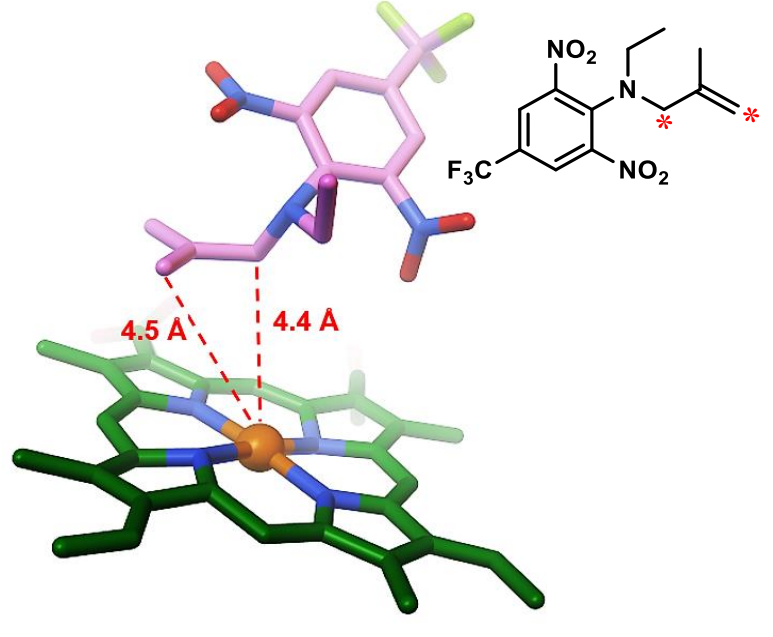

d

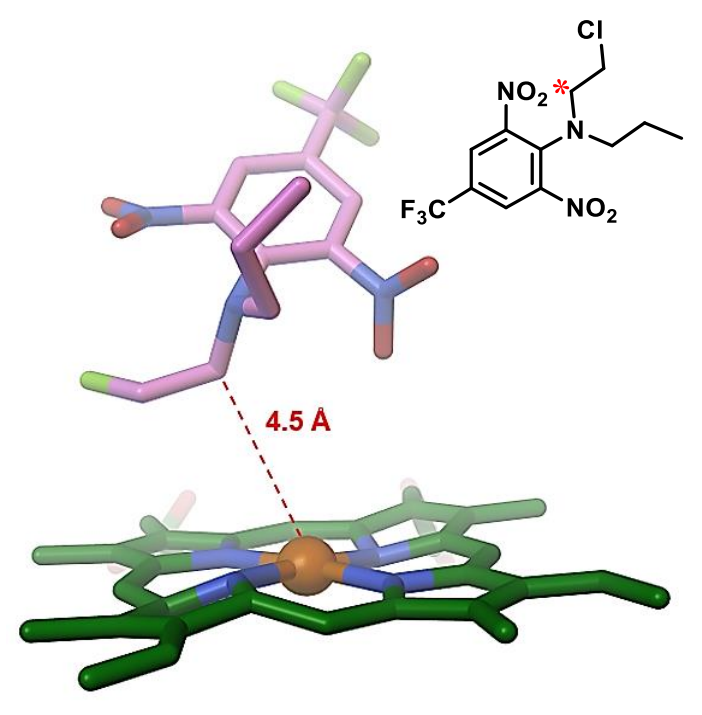


Fig. S9 View of the best affinity score pose of oryzalin in the model of the CYP706A3 active site showing the H-bonding interactions between sulfonamide group and Asn 122 and Glu 128 residues on the top of the active site.

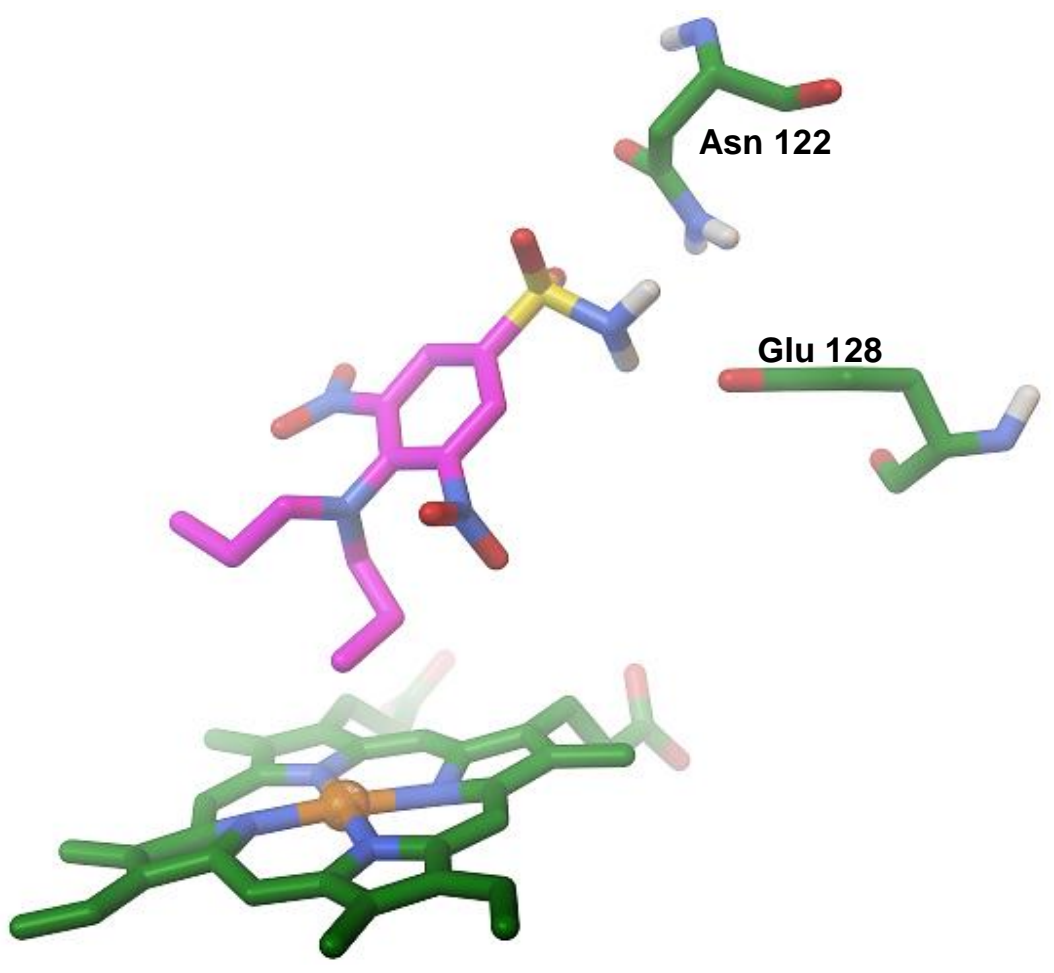


Fig. S10 Dinitroaniline conversion by other sesquiterpene-metabolizing enzymes detected by highperformance liquid chromatography and diode array detection (HPLC-DAD). Fifty ml cultures of empty vector- or P450-transfomrmed yeasts were incubated in $100 \mathrm{ml}$ Erlenmeyer flasks with 200 $\mu \mathrm{M}$ of herbicide for 24 hours at $20^{\circ} \mathrm{C}$ and with shaking at $180 \mathrm{rpm}$. Culture supernatants were collected after centrifugation at 2,800 $\mathrm{g}$ for $10 \mathrm{~min}$ and were extracted and concentrated using solid phase extraction cartridges, injected on HPLC-DAD. Note that better culture aeration of the culture as compared to Fig. 8 improves P450-mediated herbicide conversion. 
Fluchloralin

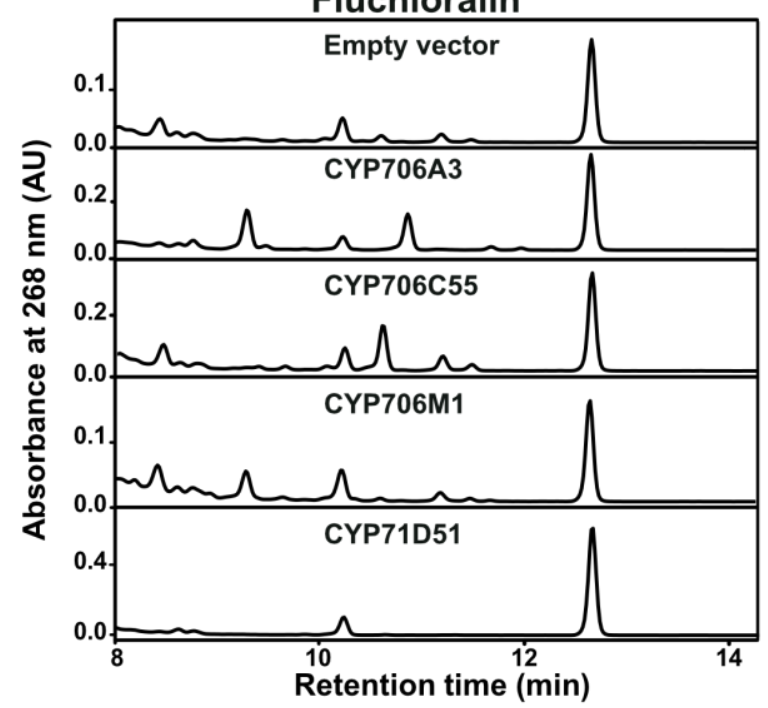

Ethalfluralin

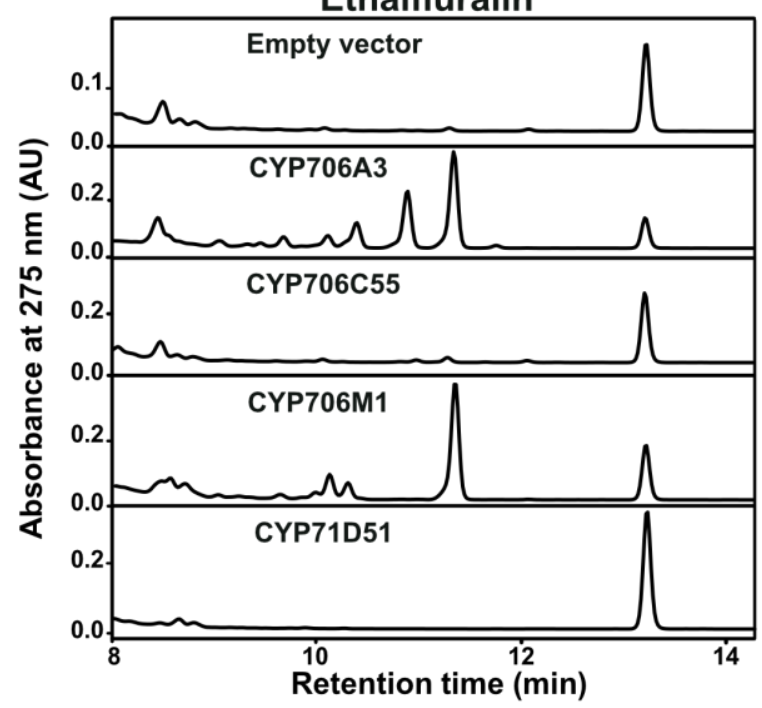

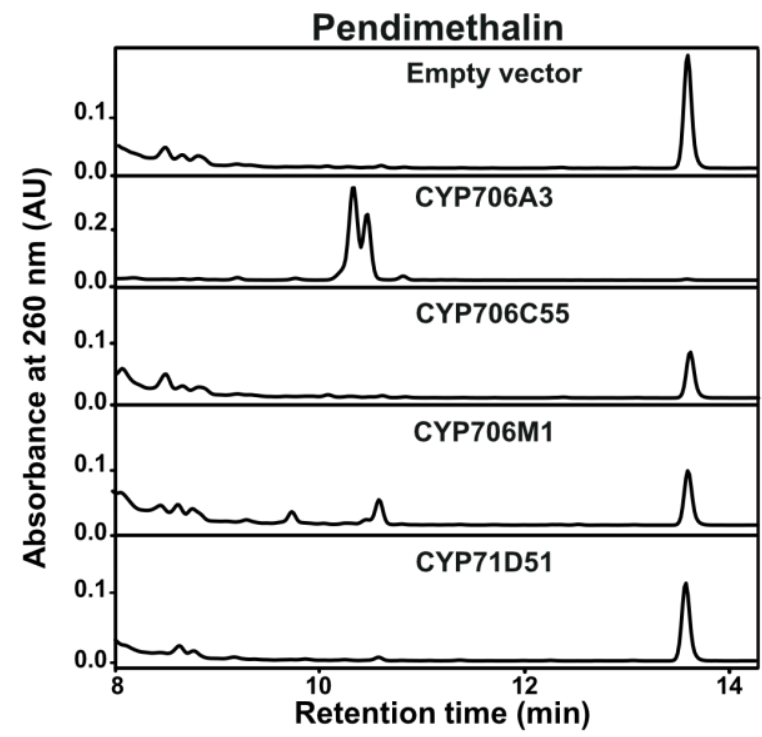

Benefin

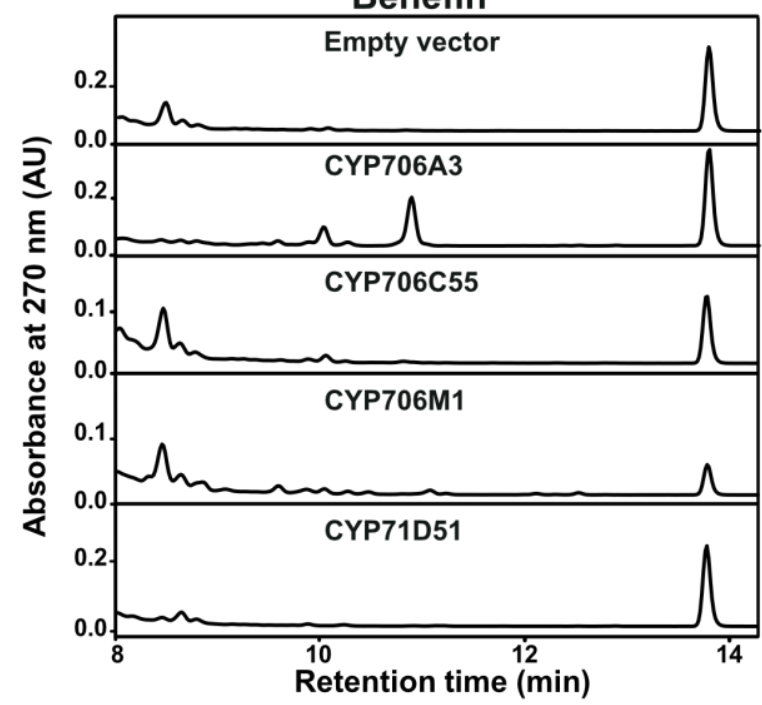

\section{Trifluralin}

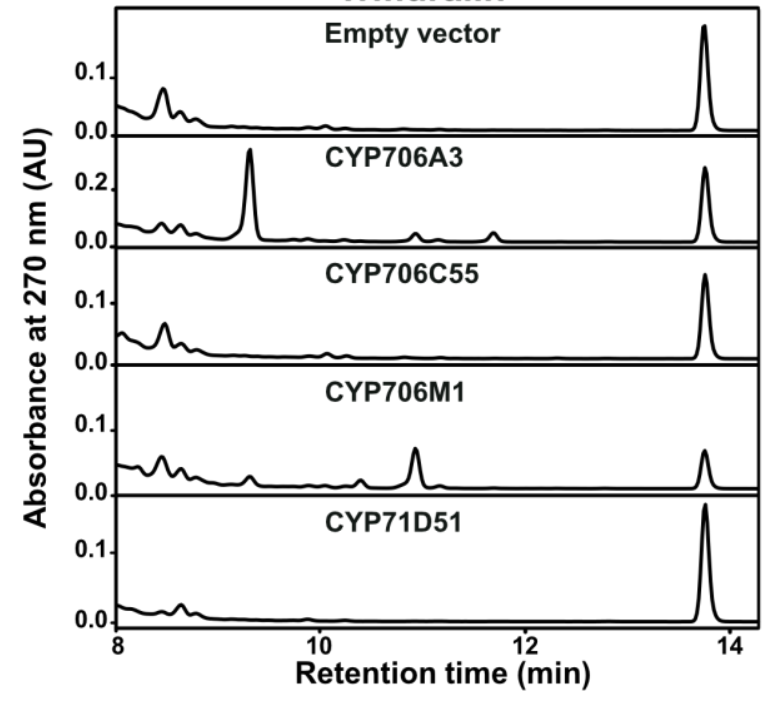


Fig. S11 Oryzalin conversion by other sesquiterpene-metabolizing enzymes detected by highperformance liquid chromatography and diode array detection (HPLC-DAD).

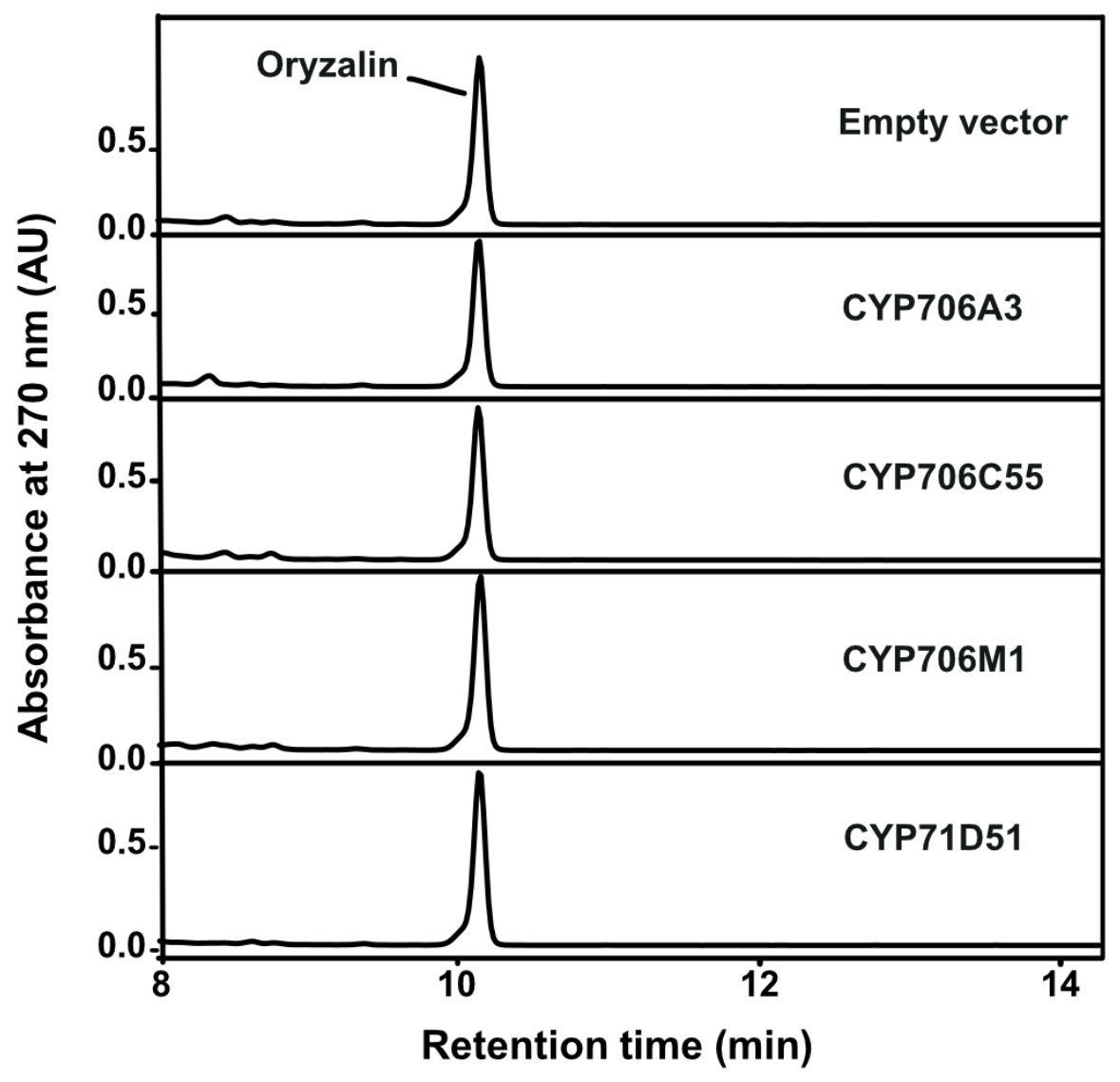


Table S1 Herbicides tested as substrates of the plant P450 enzyme.

Chemical Family Active Ingredients $\quad$ MW (g/mol) $\quad$ Structure

Dinitroanilines $\quad$ Pendimethalin 281.3<smiles>CCC(CC)Nc1c([N+](=O)[O-])cc(C)c(C)c1[N+](=O)[O-]</smiles>

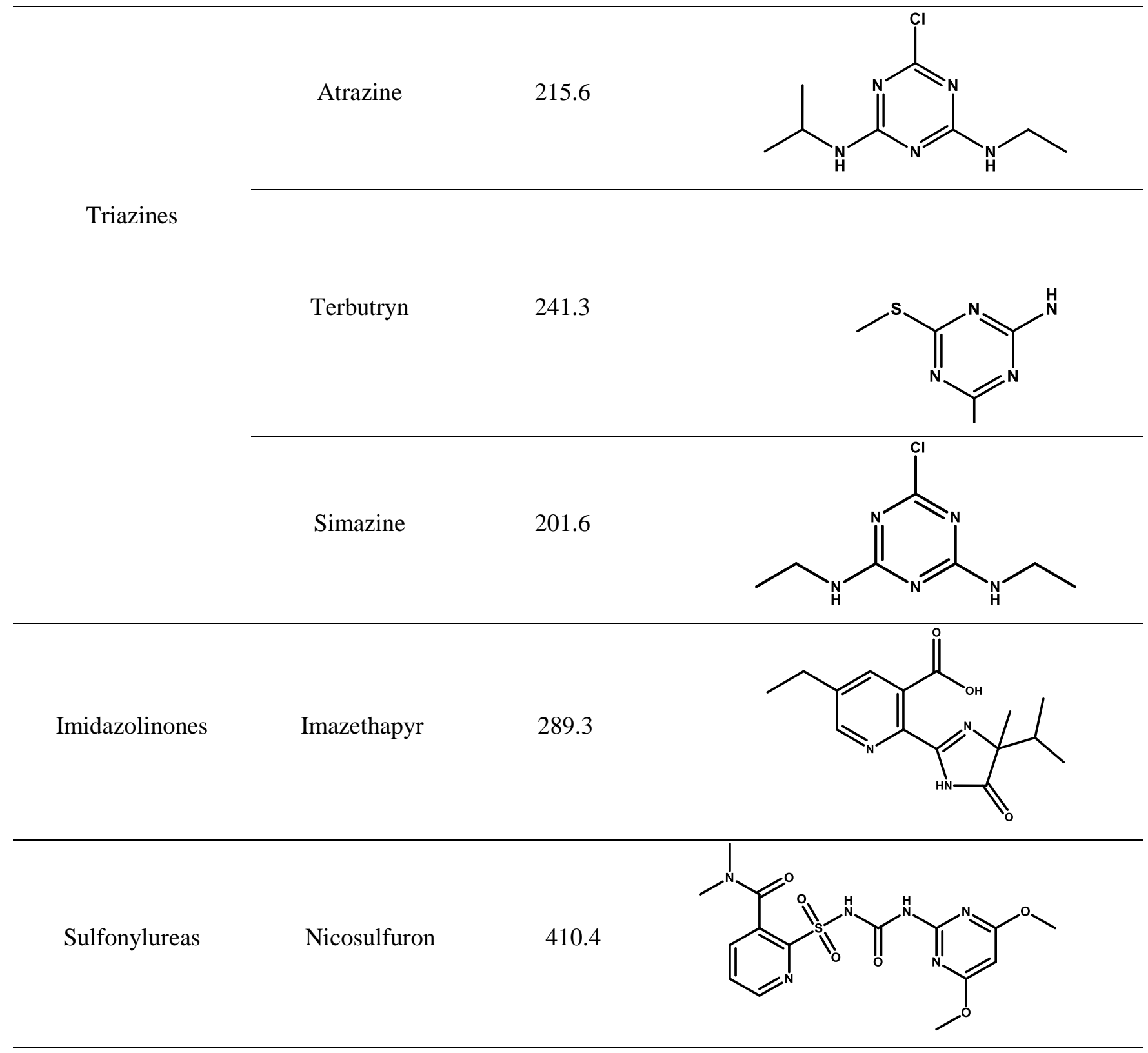




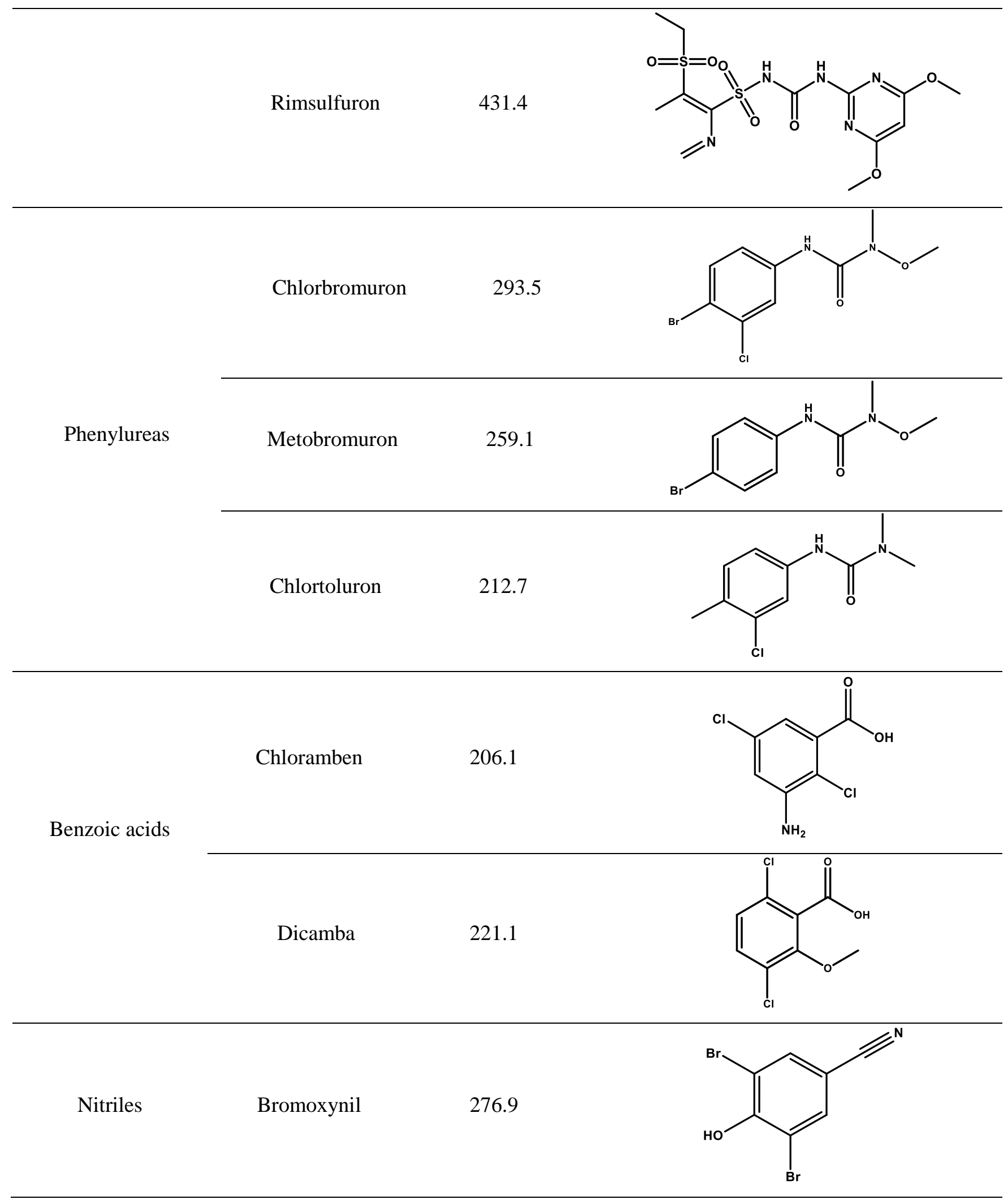




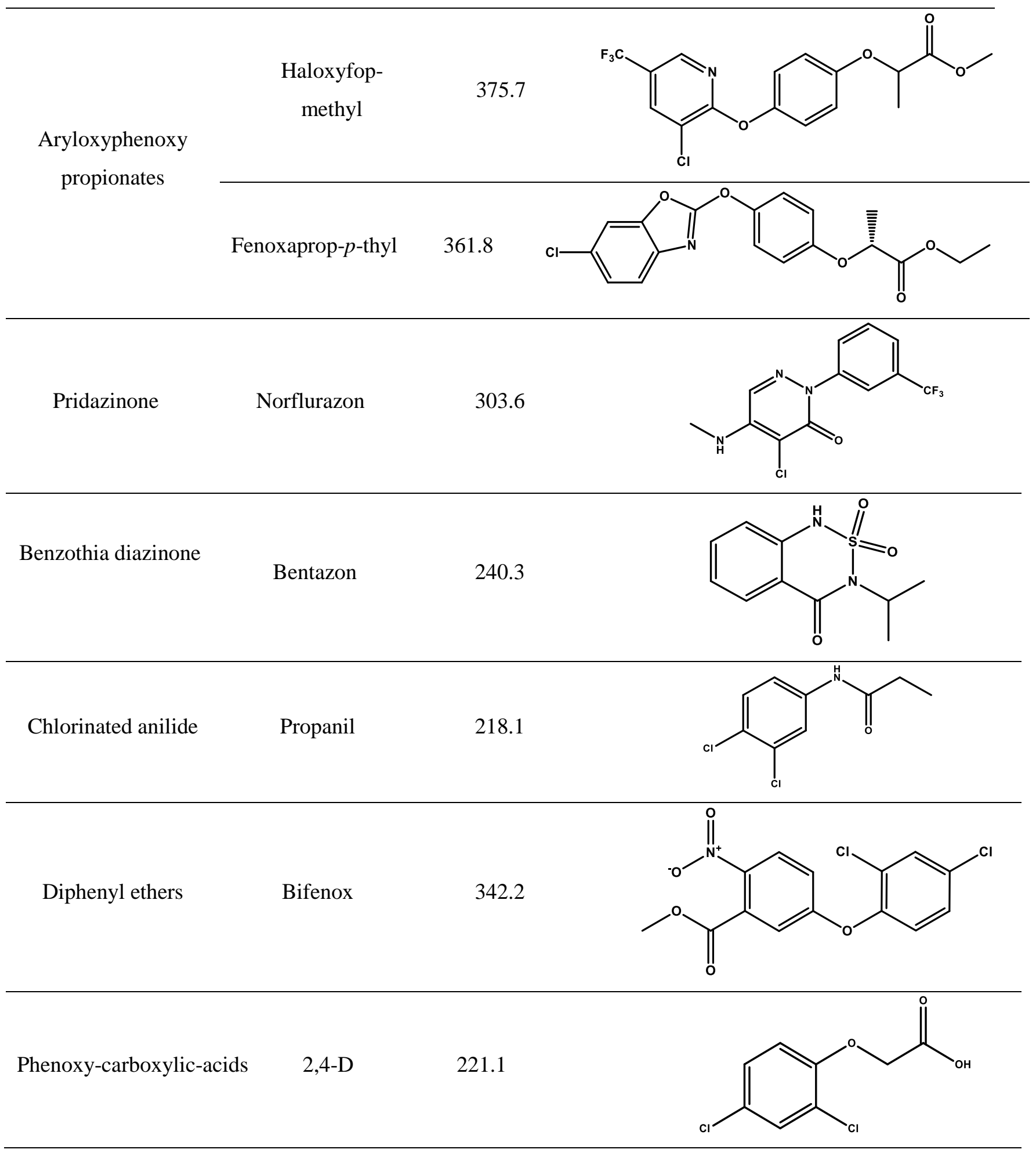


Table S2 Quantification of P450 expression in yeast.P450 was quantified in recombinant yeast microsomal fractions by differential spectrophotometry as described in the Material and Methods section.

\begin{tabular}{cc}
\hline P450 enzyme & $\begin{array}{c}\text { P450 concentration } \\
(\boldsymbol{\mu M})\end{array}$ \\
\hline CYP72A224 & 1.63 \\
CYP73A92 & 0.55 \\
CYP98A23 & 0.56 \\
CYP98A27 & 0.67 \\
CYP706A3 & 0.17 \\
CYP76B1 & 0.77 \\
CYP706C55 & 1.9 \\
CYP706M1 & 0.12 \\
CYP71D51 & 0.21 \\
\hline
\end{tabular}


Table S3 Screening for CYP-dependent herbicide oxidation. Microsomal membranes from yeasts transformed with P450 expression vectors were incubated with herbicides $(100 \mu \mathrm{M})$ for 20 min in the presence of NADPH $(300 \mu \mathrm{M})$. (+) Herbicide was converted; (-) herbicide was not converted. Yeast transformed with an empty vector was used as a negative control.

\begin{tabular}{|c|c|c|c|c|c|c|c|}
\hline \multirow{2}{*}{ Family } & \multirow{2}{*}{ Herbicide } & \multicolumn{6}{|c|}{ Conversion } \\
\hline & & CYP98A23 & CYP98A27 & CYP706A3 & CYP73A98 & CYP72A224 & CYP76B1 \\
\hline \multirow[t]{2}{*}{ Dinitroaniline } & Pendimethalin & - & - & + & - & - & - \\
\hline & Atrazine & - & - & - & - & - & - \\
\hline \multirow[t]{2}{*}{ Triazines } & Terbutryn & - & - & - & - & - & - \\
\hline & Simazine & - & - & - & - & - & - \\
\hline Imidazolinones & Imazethapyr & - & - & - & - & - & - \\
\hline \multirow{2}{*}{ Sulfonylureas } & Nicosulfuron & - & - & - & - & - & - \\
\hline & Rimsulfuron & - & - & - & - & - & - \\
\hline \multirow{3}{*}{ Phenylureas } & Chlorbromuron & - & - & - & - & - & + \\
\hline & Metobromuron & - & - & - & - & - & + \\
\hline & Chlortoluron & - & - & - & - & - & + \\
\hline \multirow{2}{*}{ Benzoic acids } & Chloramben & - & - & - & - & - & - \\
\hline & Dicamba & - & - & - & - & - & - \\
\hline Nitriles & Bromoxynil & - & - & - & - & - & - \\
\hline \multirow{2}{*}{$\begin{array}{l}\text { Aryloxyphenoxy } \\
\text { propionates }\end{array}$} & $\begin{array}{l}\text { Haloxyfop- } \\
\text { methyl }\end{array}$ & - & - & - & - & - & - \\
\hline & $\begin{array}{l}\text { Fenoxaprop-p- } \\
\text { ethyl }\end{array}$ & - & - & - & - & - & - \\
\hline Pridazinone & Norflurazon & - & - & - & - & - & - \\
\hline
\end{tabular}




\begin{tabular}{|c|c|c|c|c|c|c|c|}
\hline $\begin{array}{l}\text { Benzothia } \\
\text { diazinone }\end{array}$ & Bentazon & - & - & - & - & - & - \\
\hline $\begin{array}{l}\text { Chlorinated } \\
\text { anilide }\end{array}$ & Propanil & - & - & - & - & - & - \\
\hline Diphenyl ethers & Bifenox & - & - & - & - & - & - \\
\hline $\begin{array}{l}\text { Phenoxy- } \\
\text { carboxylic-acids }\end{array}$ & $2,4-\mathrm{D}$ & - & - & - & - & - & - \\
\hline
\end{tabular}


Table S4 Summary of parameters estimated from the log-logistic model (Eq. 1) fitted for plant fresh weight of the CaMV35S:CYP706A3 transformed Arabidopis thaliana plant versus wild-type (WT).

\begin{tabular}{|c|c|c|c|c|c|c|c|c|c|}
\hline \multirow{2}{*}{ Herbicide } & \multicolumn{4}{|c|}{ Fresh weight of wild type (\% control) } & \multicolumn{4}{|c|}{ Fresh weight of 35S:CYP706A3 (\% control) } & \multirow{2}{*}{$\begin{array}{c}\text { Tolerance } \\
\text { factor }\end{array}$} \\
\hline & b & c & d & e $\left(\mathrm{IC}_{50}\right)$ & b & c & d & e $\left(\mathrm{IC}_{50}\right)$ & \\
\hline Pendimethalin & $1.05(0.2)$ & $-2.9(1.6)$ & $129(21)$ & $0.15(0.04)$ & $2.7(0.3)$ & $-25.9(10)$ & $93.2(1.2)$ & $7.8(0.6)$ & 52 \\
\hline Trifluralin & $1.6(0.2)$ & $-5.3(2.4)$ & $93.6(3.1)$ & $0.8(0.1)$ & $2.7(0.3)$ & $-25.9(10)$ & $95.5(1.4)$ & $7.7(0.5)$ & 10 \\
\hline Fluchloralin & $16.4(8.5)$ & $0.4(0.8)$ & $90.5(1.3)$ & $0.6(0.07)$ & $3.1(0.2)$ & $-23(7.5)$ & $96.4(0.9)$ & $7.4(0.4)$ & 12 \\
\hline Benefin & $1.9(0.2)$ & $-3.4(1.6)$ & $96.8(1.6)$ & $1.1(0.06)$ & $2.4(0.2)$ & $-20(7.6)$ & $1.3(0.06)$ & $7.4(0.5)$ & 7 \\
\hline Ethalfluralin & $1.8(0.2)$ & $-4.8(2.6)$ & $96.9(2.3)$ & $1.3(0.08)$ & $1.9(0.2)$ & $-34(14)$ & $91.8(1.7)$ & $8.8(1.04)$ & 7 \\
\hline Oryzalin & $0.5(0.08)$ & $-90(37)$ & $105(6.1)$ & $9.9(6.7)$ & $0.5(0.07)$ & $-95(36)$ & $108.6(5.8)$ & $10.2(6.9)$ & 1 \\
\hline
\end{tabular}

b, slope of curve; c lower limit; d, upper limit; e(IC50), the dose required to inhibit the growth of plant by $50 \%$.

Values in parentheses in each column are the standard errors of parameters. Tolerance factors $\left(\mathrm{IC}_{50} C Y P 706 A 3 / \mathrm{IC}_{50} \mathrm{WT}\right)$. 
Methods S1 LC-MS data processing. Row formula annotations were performed using Metaboscape 3.0 (Bruker) software. All adduct forms were grouped to form a "bucket", representing one single metabolite feature used for annotations. An intensity threshold of 1,000 was applied for the extraction of metabolite features. The untargeted annotations were performed with a criterion of mass deviation $(\Delta \mathrm{m} / \mathrm{z})$ under $3 \mathrm{ppm}$ and $\mathrm{mSigma}$ value under 30 to assess the good fit of the isotope pattern. The smart Formula tool was applied to perform raw formula annotations using C, H, N, O, P, S. Metabolite Predict 2.0 (Bruker) was used for in silico prediction of catabolites and conjugates using the "all rules" template of the software, consisting of 79 distinct biotransformation rules. Using the chemical structure of the parent drug and performing identity and valence checks with the optimized results, Metabolite Predict 2.0 derived possible metabolites, resulting in a "preferred mass list". Metabolite Predict 2.0 also returned information about the enzyme involved in the metabolic process leading to the predicted metabolites (catabolites or conjugates). Metabolite Predict 2.0 was used to generate metabolites in two generations: original molecules were subjected to rules of biotransformation, then the first generation metabolites obtained were subjected to the same rules to obtain second-generation metabolites. The obtained preferred mass lists were subsequently used as analyte list for annotation in Metaboscape 3.0. Tentative identifications were performed comparing raw formula annotations by Smart Formula tool and the annotations obtained with the analyte list created from Metabolite Predict. 
Methods S2 Herbicide docking extended information. For each herbicide conformer, the number of generated poses can vary under Smina protocol, which has been created for facilitating the implementation of different scoring functions (Koes et al., 2013). In this study, three different scoring functions were applied and compared based on the position of experimental metabolism site observed for pendimethalin, namely the native Vina (Trott et al., 2010), the Dkoes (Koes et al., 2013), and the Vinardo score (Quiroga and Viallarreal, 2016). All these scoring functions gave the docking pose with the subterminal $\mathrm{CH} 2$ site of the alkyl chain of pendimethalin closest to heme iron as the first ranked pose (lowest energy), consistently with observed metabolism. The default Vina scoring function was found to be the most discriminating in ranking energies and was finally selected for the whole series of docking experiments. The score, expressed in $\mathrm{kcal}^{\mathrm{mol}}{ }^{-1}$ by Autodock Vina, can be considered as an estimated free energy of ligand binding (indicative of binding affinity), and the generated conformations are ranked by their binding score.

\section{Notes S1 NMR determination}

\section{3-((3,4-dimethyl-2,6-dinitrophenyl)amino)pentan-2-ol}

Diastereoisomer 1: ${ }^{1} \mathbf{H}$ NMR $\left(\mathbf{C D C l}_{3}, \mathbf{5 0 0} \mathbf{~ M H z}\right): \delta=8.07(\mathrm{~s}, 1 \mathrm{H}), 7.89(\mathrm{~d}, J=10.7 \mathrm{~Hz}$, $1 \mathrm{H}), 3.88(\mathrm{qd}, J=6.3,3.4 \mathrm{~Hz}, 1 \mathrm{H}), 3.05(\mathrm{dtd}, J=10.1,6.6,3.4 \mathrm{~Hz}, 1 \mathrm{H}), 2.27$ (s, 3H), 2.17 (s, $3 \mathrm{H}), 1.64(\mathrm{dp}, J=14.4,7.3 \mathrm{~Hz}, 1 \mathrm{H}), 1.56(\mathrm{~s}, 1 \mathrm{H}), 1.52-1.45(\mathrm{~m}, 1 \mathrm{H}), 1.20(\mathrm{~d}, J=6.4 \mathrm{~Hz}$, $3 \mathrm{H}), 0.90(\mathrm{t}, J=7.4 \mathrm{~Hz}, 3 \mathrm{H}) \mathrm{ppm} .{ }^{13} \mathbf{C} \mathbf{N M R}\left(\mathbf{C D C l}_{3}, \mathbf{1 2 5} \mathbf{M H z}\right): \delta=142.6,138.1,137.1$, 134.6, 128.4, 125.8, 68.5, 61.4, 26.0, 20.5, 19.4, 15.4, $10.3 \mathrm{ppm}$.

Diastereoisomer 2: ${ }^{1} \mathbf{H}$ NMR $\left(\mathbf{C D C l}_{3}, \mathbf{5 0 0} \mathbf{~ M H z}\right): \delta=8.06(\mathrm{~s}, 1 \mathrm{H}), 7.59$ (d, $J=10.8 \mathrm{~Hz}$, $1 \mathrm{H}), 3.89-3.82(\mathrm{~m}, 1 \mathrm{H}), 3.24-3.17(\mathrm{~m}, 1 \mathrm{H}), 2.27(\mathrm{~s}, 3 \mathrm{H}), 2.18(\mathrm{~s}, 3 \mathrm{H}), 1.63-1.56(\mathrm{~m}, 1 \mathrm{H})$, $1.56(\mathrm{~s}, 1 \mathrm{H}), 1.51-1.42(\mathrm{~m}, 1 \mathrm{H}), 1.14(\mathrm{~d}, J=6.6 \mathrm{~Hz}, 3 \mathrm{H}), 0.98-0.92(\mathrm{t}, J=7.4 \mathrm{~Hz}, 3 \mathrm{H})$ ppm. ${ }^{13} \mathbf{C}$ NMR (CDCl3, 125 MHz): $\delta=143.0,138.1,137.1,135.0,128.3,126.3,69.6,61.6$, $23.9,19.4,18.1,15.4,10.7 \mathrm{ppm}$.<smiles>CCC(Nc1c([N+](=O)[O-])cc(C)c(C)c1[N+](=O)[O-])C(C)O</smiles> 